\title{
Global epidemiology, health burden and effective interventions for elevated blood pressure and hypertension
}

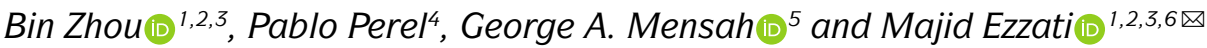

Abstract | High blood pressure is one of the most important risk factors for ischaemic heart disease, stroke, other cardiovascular diseases, chronic kidney disease and dementia. Mean blood pressure and the prevalence of raised blood pressure have declined substantially in high-income regions since at least the 1970s. By contrast, blood pressure has risen in East, South and Southeast Asia, Oceania and sub-Saharan Africa. Given these trends, the prevalence of hypertension is now higher in low-income and middle-income countries than in high-income countries. In 2015, an estimated 8.5 million deaths were attributable to systolic blood pressure $>115 \mathrm{mmHg}, 88 \%$ of which were in low-income and middle-income countries. Measures such as increasing the availability and affordability of fresh fruits and vegetables, lowering the sodium content of packaged and prepared food and staples such as bread, and improving the availability of dietary salt substitutes can help lower blood pressure in the entire population. The use and effectiveness of hypertension treatment vary substantially across countries. Factors influencing this variation include a country's financial resources, the extent of health insurance and health facilities, how frequently people interact with physicians and non-physician health personnel, whether a clear and widely adopted clinical guideline exists and the availability of medicines. Scaling up treatment coverage and improving its community effectiveness can substantially reduce the health burden of hypertension.

High blood pressure is one of the most important risk factors for ischaemic heart disease, stroke, other cardiovascular diseases (CVDs), chronic kidney disease and dementia $^{1-10}$. Elevated blood pressure is a leading preventable cause of CVD mortality and disease burden, globally and in most regions of the world ${ }^{11-13}$. One of the global non-communicable disease (NCD) targets adopted by the World Health Assembly in 2013 is to lower the prevalence of raised blood pressure by $25 \%$ by 2025 compared with its 2010 level $^{12,14}$. Raised blood pressure is defined as systolic blood pressure $(\mathrm{SBP}) \geq 140 \mathrm{mmHg}$ or diastolic blood pressure (DBP) $\geq 90 \mathrm{mmHg}$.

In this Review, we summarize the current data on the global epidemiology of blood pressure and hypertension and evaluate how they have changed over time. We also present estimates of the mortality effects of elevated blood pressure and summarize interventions that can reduce the burden of high blood pressure. To begin, we give a brief historical overview of how blood pressure came to be established as an important risk factor for CVDs and other diseases, emphasizing the global nature of early research. We then review the data on worldwide levels and trends in blood pressure and hypertension, effects on mortality, and major causes of high and low blood pressure. We also review how blood pressure might be lowered in different populations, emphasizing how epidemiological evidence can be used in real-world conditions. Finally, we briefly present issues related to the global epidemiology of hypertension and its management in the context of the coronavirus disease 2019 (COVID-19) pandemic.

\section{History of blood pressure and hypertension}

Early knowledge and measurements. In the Yellow Emperor's Classic of Medicine (first written approximately 200-400 BCE), the Yellow Emperor of China (approximately 2600-2700 BCE) was believed to have talked about the so-called 'hard pulse disease', claiming that 'if too much salt is used in food, the pulse hardens' and suggested the use of venesection for treatment ${ }^{15,16}$. Physicians in ancient Egypt (approximately 1500 BCE) and India (approximately $150 \mathrm{BCE}$ ) also noted the relationship between pulse quality and the development 


\section{Key points}

- Hypertension is more prevalent in low-income and middle-income countries than in high-income countries.

- In 2015, 8.5 million deaths were associated with high blood pressure, $88 \%$ of which were in low-income and middle-income countries.

- Population-level measures, such as increasing the availability and affordability of fresh fruits and vegetables and lowering the sodium content of packaged and prepared foods, can lower blood pressure in the entire population.

- Effective use of pharmacological treatment for people with hypertension varies substantially globally and is particularly low in low-income and middle-income countries.

- Scaling up treatment coverage and improving its effectiveness can substantially reduce the health burden of hypertension.

of afflictions of the heart and brain ${ }^{17}$. Pulse also had an essential role in ancient Greek medicine, and its relationship with environment and disease was discussed at length by physicians including Hippocrates (460-370 BCE), Erasistratus (304-250 BCE) and Galen $(130-210 \mathrm{CE})^{16-19}$. However, these physicians did not note the connection between apoplexy and high blood pressure or hardening of the pulse ${ }^{16}$.

In 1628, William Harvey described the process of blood flowing out of the heart and then returning to the heart via arteries, peripheries and veins ${ }^{17,20}$. Nearly 300 years later, blood pressure was discovered, and a reliable method for its measurement was devised. Even before this technology was developed, the work of a few physicians, including Richard Bright and Frederick Akbar Mahomed, led to the first description of essential hypertension in the nineteenth century, for example, hypertension in the absence of renal disease $e^{16,17,21}$.

The first accurate, direct measurement of human blood pressure was performed by the surgeon Faivre with the use of a mercury manometer during a limb amputation in 1856, with a reported arterial blood pressure of $115-120 \mathrm{mmHg}\left(\mathrm{REFS}^{22,23}\right)$. Devices for the indirect measurement of blood pressure (that is, to measure the counter-pressure needed to stop the blood flow in an artery) evolved from the first sphygmograph to visualize pulse waves, invented by Karl Vierordt in 1855, to Samuel Siegfried Ritter von Basch's sphygmomanometer in 1880 (REF. ${ }^{23}$ ). In 1896, Scipione Riva Rocci invented an inflatable cuff that compressed around the whole circumference of the arm to apply uniform pressure. The cuff size was later changed to $12 \mathrm{~cm}$ in 1901 from the original $5 \mathrm{~cm}\left(\mathrm{REFS}^{22,23}\right)$, and it became the prototype of cuffs that continue to be used in modern devices.

\footnotetext{
Author addresses

${ }^{1}$ Department of Epidemiology and Biostatistics, School of Public Health, Imperial College London, London, UK.

${ }^{2}$ MRC Centre for Environment and Health, School of Public Health, Imperial College London, London, UK.

${ }^{3}$ The Abdul Latif Jameel Institute for Disease and Emergency Analytics, School of Public Health, Imperial College London, London, UK.

${ }^{4}$ Department of Non-communicable Disease Epidemiology, London School of Hygiene \& Tropical Medicine, London, UK.

${ }^{5}$ Center for Translation Research and Implementation Science, National Heart, Lung, and Blood Institute, National Institutes of Health, Bethesda, MD, USA.

${ }^{6}$ Regional Institute for Population Studies, University of Ghana, Accra, Ghana.
}

In 1905, Nikolai Korotkoff, a Russian surgeon, reported a method that uses the tapping sounds detected through a stethoscope at different phases during the deflation of the cuff to determine the pressure at which blood flow was completely blocked, that is, SBP, and the pressure at which blood flow was no longer restrained, that is, $\mathrm{DBP}^{22,23}$. Together, Korotkoff's auscultatory technique and Rocci's cuff formed the basis of modern blood pressure measurement devices.

Blood pressure as a risk factor. The quantitative connection between high blood pressure and mortality was first revealed in studies with the use of insurance data at the beginning of the twentieth century $y^{24,25}$. These data also revealed that blood pressure rises with age and is higher in those who have higher weight for their height ${ }^{26}$. The Framingham Heart Study ${ }^{27}$ showed a greater risk of coronary heart disease in men and women with hypertension (defined as SBP $\geq 160 \mathrm{mmHg}$ or $\mathrm{DBP} \geq 95 \mathrm{mmHg}$ ) than in individuals with SBP $<140 \mathrm{mmHg}$ and DBP $<90 \mathrm{mmHg}$. The study also showed an increased risk of CVD in those with high-normal blood pressure, that is, $130-139 \mathrm{mmHg}$ for SBP and $85-89 \mathrm{mmHg}$ for DBP, compared with those with optimal blood pressure, defined as SBP $<120 \mathrm{mmHg}$ and $\mathrm{DBP}<80 \mathrm{mmHg}\left(\mathrm{REF}^{28}\right)$. The Prospective Studies Collaboration pooled 61 prospective observational studies with 1 million participants in Asia, Australasia, Canada, Europe and the USA and found a doubling of the risk of ischaemic heart disease and stroke with every $20 \mathrm{mmHg}$ and $10 \mathrm{mmHg}$ increase in SBP and DBP, respectively, starting from as low as $115 \mathrm{mmHg}$ for SBP and $75 \mathrm{mmHg}$ for $\mathrm{DBP}^{5}$. The Asia Pacific Cohort Studies Collaboration found similar associations in Asian and Australasian populations ${ }^{6,8}$. On the basis of observational studies, each $10 \mathrm{mmHg}$ increase in SBP is associated with a $45 \%$ higher risk of ischaemic heart disease and about a $65 \%$ higher risk of ischaemic or haemorrhagic stroke in those aged 55-64 years ${ }^{5,8}$. The relative risk is inversely associated with age ${ }^{8}$.

The observational results were confirmed by data from clinical trials that lowered blood pressure. These trials included the VA Cooperative Trials, Multiple Risk Factor Intervention Trial (MRFIT), and those included in the Blood Pressure Lowering Treatment Trialists' Collaboration ${ }^{7,29-34}$. Other trials, including the Systolic Blood Pressure Intervention Trial (SPRINT), and meta-analyses of trials further showed reductions in CVD events but mixed results for cardiovascular and all-cause mortality with intensive blood pressure lowering to levels below the conventional cut-off for hypertension of $140 / 90 \mathrm{mmHg}$, for example, SBP of $120-130 \mathrm{mmHg}\left(\mathrm{REFS}^{2-4,35-37}\right)$. However, most of the trials have been performed in Western populations, and trial evidence is especially scarce for Africa, Latin America and South Asia.

\section{Global, regional and national levels}

National and multi-country studies. Supplementary Table 1 summarizes the studies that investigated blood pressure and hypertension trends in individual countries $^{38-67}$ for a period of $\geq 20$ years. The studies that compared multiple countries ${ }^{68-95}$ are summarized in 


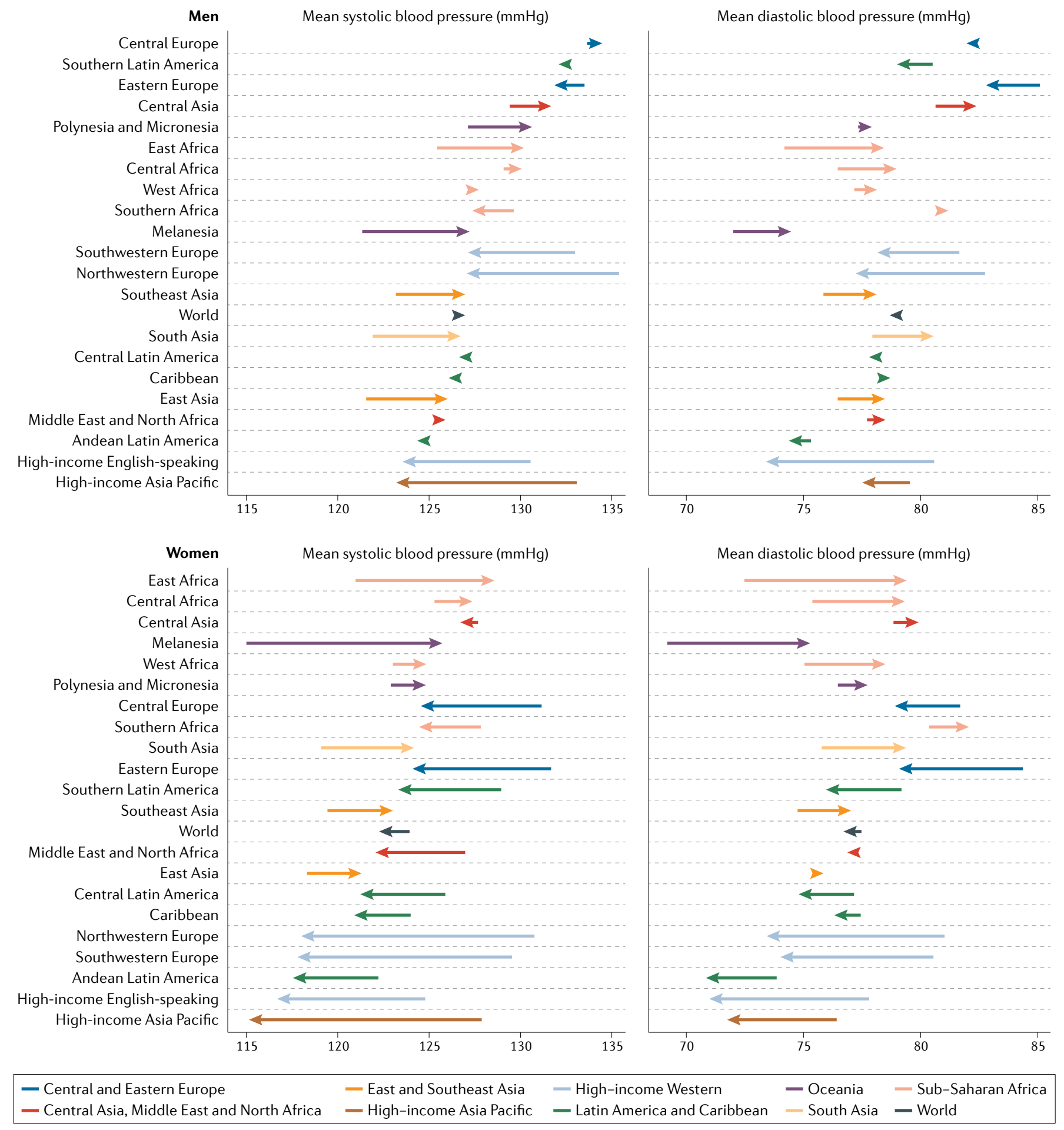

Fig. 1 | Changes in blood pressure by region. Changes in age-standardized mean systolic and diastolic blood pressure between 1975 and 2015 by region. The start and end points of each arrow represent the levels of blood pressure in 1975 and 2015, respectively. Rightward arrows indicate an increase in blood pressure, and leftward arrows indicate a decrease.

Supplementary Table 2. These studies show that blood pressure has declined in high-income countries and in some middle-income countries. By contrast, blood pressure and the prevalence of hypertension have been rising or at best stagnating in the other middle-income and low-income countries, including the world's most populous countries, China and India.
Global studies. Beginning in the 2000s, some studies pooled multiple data sources to understand the global patterns of blood pressure and hypertension (Supplementary Table 2). Kearney and colleagues ${ }^{96,97}$ used data from 32 studies and estimated the global hypertension prevalence in 2000 . Mills and co-workers ${ }^{98}$ pooled 135 studies with 970,000 participants from 
Mean systolic blood pressure, men 2015

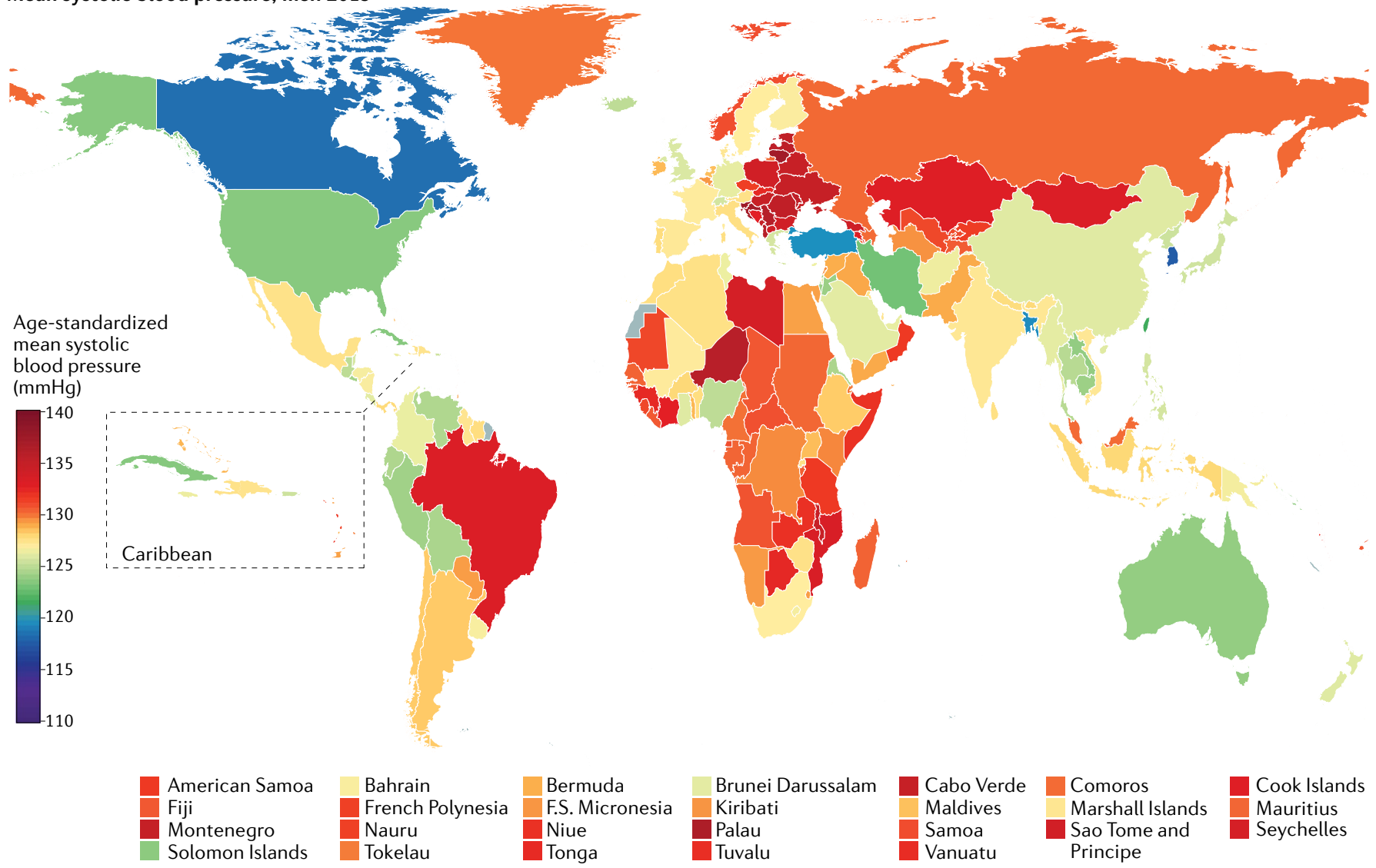

Mean systolic blood pressure, women 2015

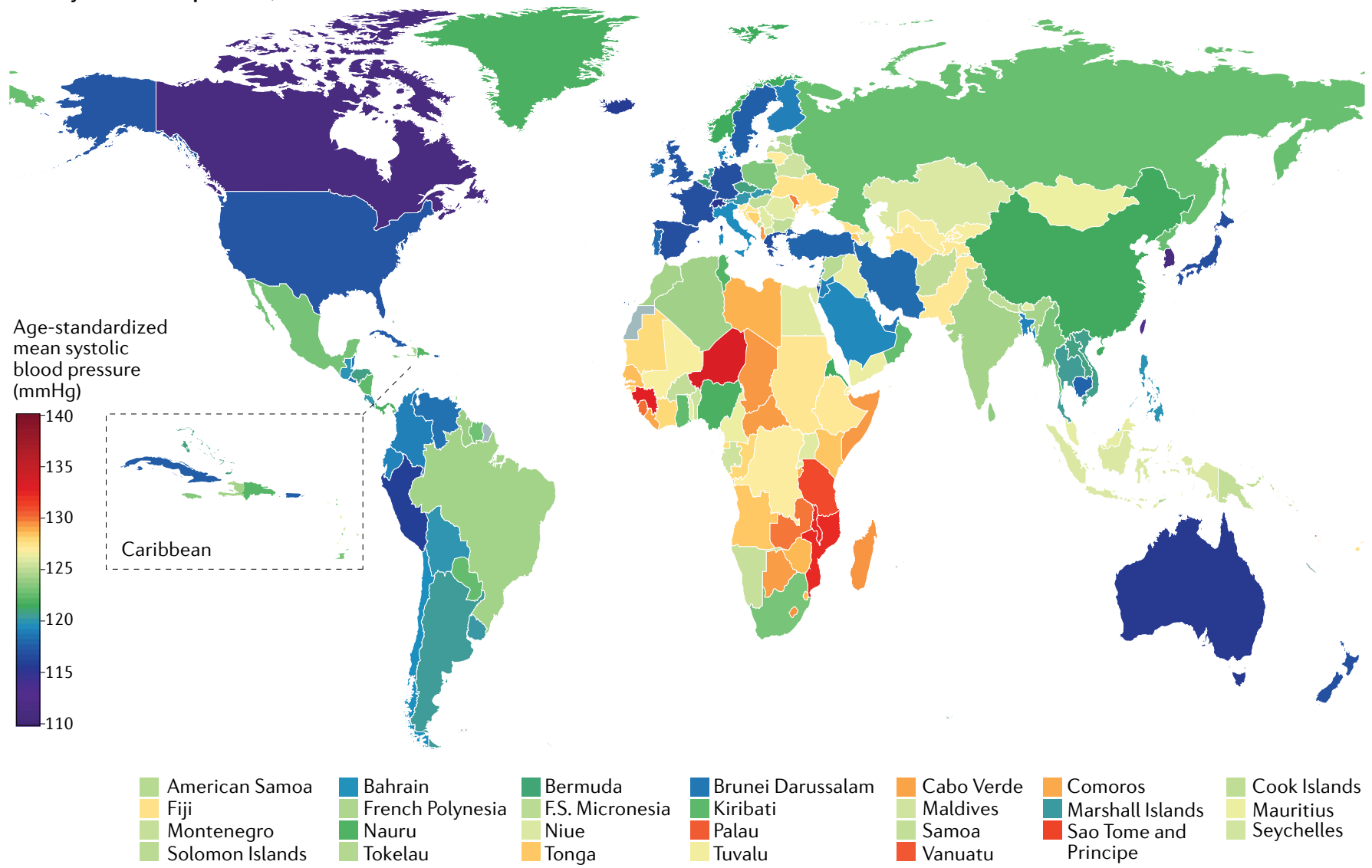


4 Fig. 2 | Worldwide systolic blood pressure. Age-standardized mean systolic blood pressure by country in 2015. Adapted from (REF. ${ }^{102}$ ), CC BY 4.0 (https://creativecommons.org/ licenses/by/4.0/). and the Caribbean, Central and Eastern Europe, Central Asia, the Middle East and North Africa. Elsewhere, the age-standardized prevalence of raised blood pressure remained unchanged, despite rising mean blood pressure.

South Korea and Canada had the lowest agestandardized mean SBP in 2015 for both men (117-118 mmHg) and women ( 111 mmHg) (FIG. 2). The highest mean SBPs in men were reported in countries in Central and Eastern Europe (for example, Croatia, Lithuania and Slovenia), Oceania, Central Asia and sub-Saharan Africa, with an age-standardized mean SBP reaching $137.5 \mathrm{mmHg}(131.2-143.8 \mathrm{mmHg})$ in Slovenia. Women in countries in sub-Saharan Africa (for example, Guinea, Malawi, Mozambique and Niger) had the highest levels of mean SBP, surpassing $132 \mathrm{mmHg}$. Countries with the lowest mean DBP were Peru and several high-income countries, including Australia, Canada, New Zealand, Singapore and the UK (FIG. 3). DBP was high throughout Central and Eastern Europe, South Asia and sub-Saharan Africa, with the age-standardized mean surpassing $85 \mathrm{mmHg}$ in Lithuanian men.

Australia, Canada, Peru, Singapore, South Korea, the UK and the USA had the lowest prevalence of raised blood pressure in 2015 for both sexes, with an age-standardized prevalence of $<13 \%$ in women and $<19 \%$ in men (FIG. 4). At the other extreme, the age-standardized prevalence surpassed 35\% among men in some countries in Central and Eastern Europe, including Croatia, Latvia, Lithuania, Hungary and Slovenia. The prevalence of raised blood pressure was $>33 \%$ among women in some countries in West Africa. standardized mean SBP in 2015 among men $\geq 18$ years of age was $127.0 \mathrm{mmHg}$, largely unchanged since 1975 . SBP declined slightly among women in the same period (from $123.9 \mathrm{mmHg}$ to $122.3 \mathrm{mmHg}$ ) (FIG. 1). Trends in the age-standardized mean DBP, which was $78.7 \mathrm{mmHg}$ for men and $76.7 \mathrm{mmHg}$ for women in 2015, were similar. The age-standardized prevalence of raised blood pressure declined globally in both sexes, from $29.5 \%$ to $24.1 \%$ among men and from $26.1 \%$ to $20.1 \%$ among women.

Mean SBP and DBP declined substantially in the high-income regions, from the highest in the world in 1975 to the lowest in 2015 (FIG. 1). The largest decline in mean SBP occurred in the high-income Asia Pacific region, by $3.2 \mathrm{mmHg}$ and $2.4 \mathrm{mmHg}$ per decade among women and men, respectively. The largest decline in mean DBP occurred in the high-income Western region: $1.8 \mathrm{mmHg}$ per decade among women and $1.5 \mathrm{mmHg}$ per decade among men. Mean SBP declined among women in Central and Eastern Europe, Latin America and the Caribbean and possibly in Central Asia, the Middle East and North Africa, albeit with larger uncertainty than in high-income regions. Similarly, mean DBP decreased in women in these regions, but the reduction was smaller than in high-income regions. Men had little or no change in mean SBP or DBP in these regions. In contrast to these declines, mean SBP and DBP have risen among men and women in East, South and Southeast Asia, Oceania and sub-Saharan Africa. The largest regional decrease in raised blood pressure was reported in the high-income regions, followed by Latin America
Blood pressure and national characteristics. Although the determinants and correlates of high versus low blood pressure at the individual level are well-established ${ }^{103}$, less is known about the association between population blood pressure and national characteristics such as national income, urbanization, diet and BMI. Two studies examined the association between population mean SBP and some national characteristics, including national income, a measure of the Western diet, the proportion of the national population living in urban areas and food share of household expenditure ${ }^{104,105}$. Next, we examine the association between mean SBP and DBP and the per capita gross domestic product (GDP), the proportion of the population living in urban areas and the age-standardized mean BMI.

FIGURE 5 shows the associations between SBP and per capita GDP, urbanization and BMI in 1975 and 2015. In 1975, mean SBP and DBP were positively associated with per capita GDP, urbanization and BMI. By 2015, the ished in men and reversed in women. Correlations for mean DBP changed similarly, but the negative correlation for women was weaker than that for mean SBP. with GDP and urbanization indicates that hypertension is not a 'disease of affluence' but one of poverty at the global level. The weakening of associations with BMI (FIG. 5) suggests that other dietary, environmental and health-care factors that also influence blood pressure are correlation between mean SBP and these factors dimin-

The changing association of mean SBP and DBP 


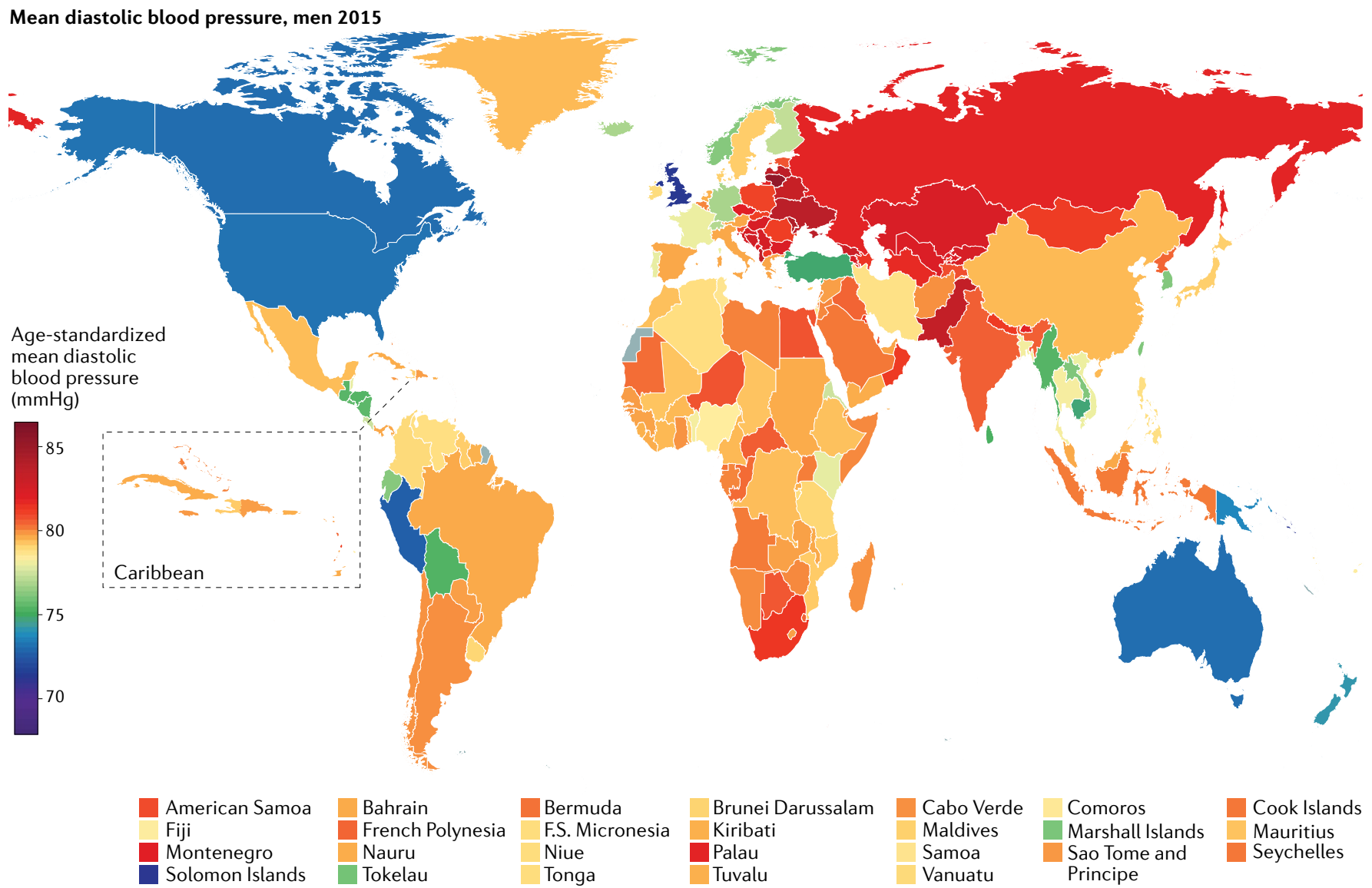

Mean diastolic blood pressure, women 2015

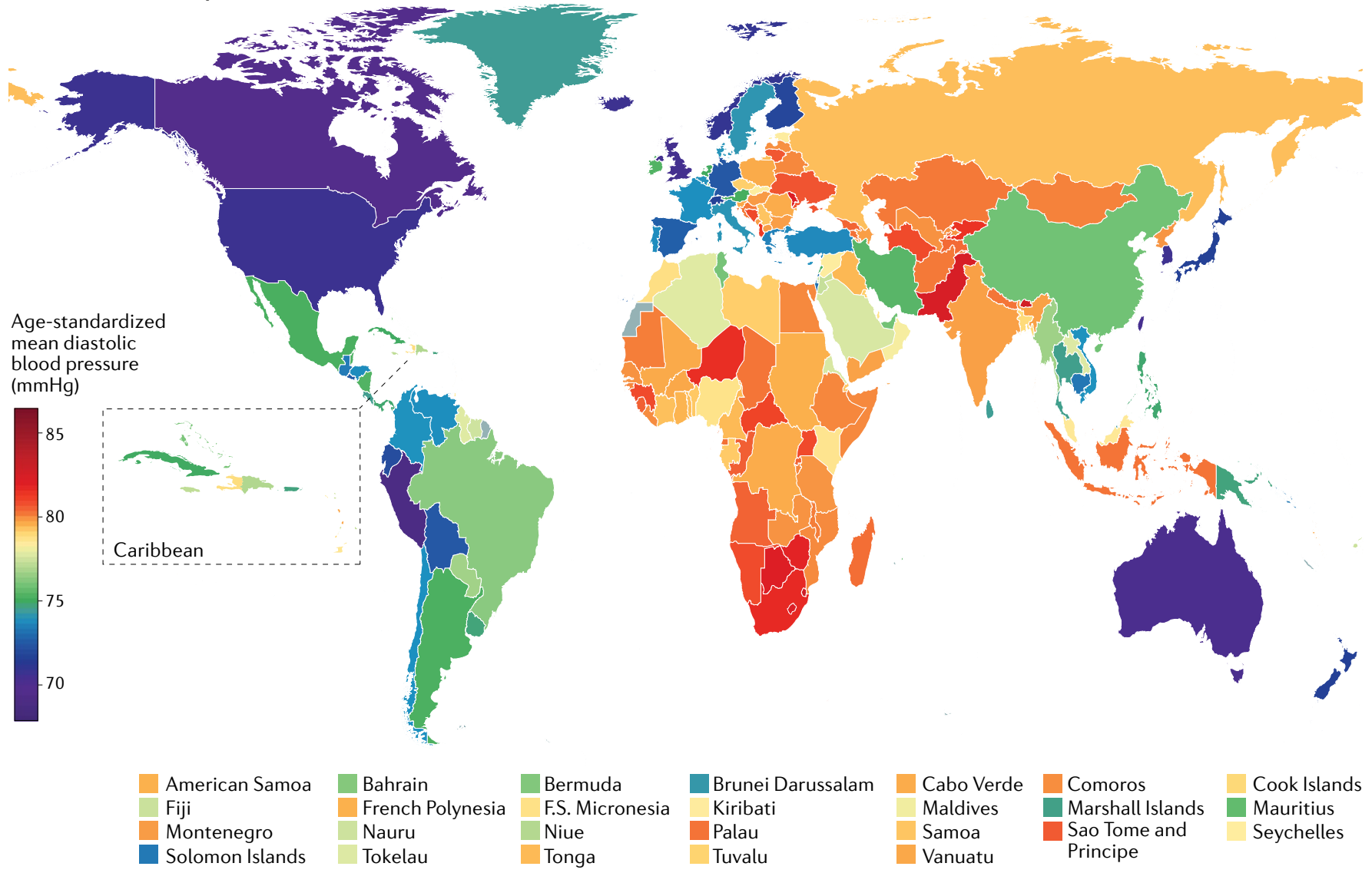


4 Fig. 3 | Worldwide diastolic blood pressure. Age-standardized mean diastolic blood pressure by country in 2015 (REF. ${ }^{102}$ ).

counteracting the effects of BMI. For example, higher income and more year-round availability of fruits and vegetables have increased their availability in most countries ${ }^{106}$. Similarly, at least in high-income countries, more people with hypertension are treated ${ }^{95}$, especially individuals with a high $\mathrm{BMI}^{107}$. Some low-income and middle-income countries with high blood pressure levels (for example, those in South Asia and sub-Saharan Africa) had one or more adverse factors, including low consumption of fresh fruits, high consumption of salt, and a high prevalence of maternal and childhood undernutrition ${ }^{106,108-112}$. The changing association between blood pressure and these country characteristics highlights the need to understand what factors drive the changes in high-income countries and in low-income and middle-income countries.

Changes in blood pressure distributions. Blood pressure is affected by nutritional, environmental and behavioural factors throughout the life course, including fetal and early childhood nutrition and growth ${ }^{113}$, adiposity ${ }^{103}$, diet (particularly sodium and potassium) $)^{114,115}$, alcohol use ${ }^{116}$, smoking ${ }^{117}$, physical activity ${ }^{118}$, air pollution ${ }^{119}$, noise ${ }^{120}$, psychosocial stress ${ }^{121}$ and the use of blood-pressurelowering medicines. Changes in some of these determinants, such as an increase in BMI and better nutrition in childhood and adolescence, can shift the entire population distribution of blood pressure and thereby change both the mean value and the prevalence of raised blood pressure. By contrast, medication and lifestyle change in those with elevated blood pressure would reduce the prevalence of raised blood pressure by affecting the high-blood-pressure tail of the distribution, with a fairly small effect on the mean blood pressure value.

An analysis of multi-country data from the WHO MONICA project revealed that different percentiles of population blood pressure distribution changed as much as its mean in most populations throughout the study period, which was about 10 years from the 1980s to the 1990s; nonetheless, the upper percentile changed by a larger amount in some communities ${ }^{71}$. The NCD-RisC found that from 1985 to 2016, in most regions where the prevalence of raised blood pressure decreased, the decline in mean blood pressure was the main driver of the decline in prevalence, contributing to at least half of the total decline ${ }^{122}$. In regions where the prevalence of raised blood pressure increased or remained unchanged, the increase was driven entirely by a rise in mean blood pressure.

The behavioural, nutritional and environmental drivers of the shift in the population distribution of blood pressure remain uncertain largely because these determinants are poorly measured. Salt intake might have declined in some countries where blood pressure declined $^{123-125}$, but it has discordant trends with blood pressure in other countries ${ }^{109,126-130}$. The prevalence of smoking has declined in most high-income countries and some middle-income countries, but remains high or is increasing in other low-income and middle-income regions ${ }^{131}$. Similarly, alcohol consumption has also had mixed trends across countries and regions ${ }^{132}$. In highincome countries, the decline in blood pressure has occurred despite rising BMI, an established risk factor for high blood pressure, whereas both BMI and blood pressure are rising in most low-income and middle-income countries ${ }^{110}$. Other potential population-wide determinants of blood pressure include increased availability and consumption of fruits and vegetables through better year-round availability ${ }^{106,108}$, central heating at home and work, which would lower winter blood pressure ${ }^{133-135}$, and improvements in early childhood and adolescent nutrition, as seen in greater adulthood body height in successive birth cohorts ${ }^{112}$. Blood pressure is also decreasing in adolescents in high-income countries and possibly some middle-income countries s $^{93,136-139}$, suggesting a role of the life-course effects from these population-wide determinants.

\section{Within country patterns}

Blood pressure in men and women. Men are known to have a higher blood pressure than women ${ }^{140}$, but this relationship could vary by age and geography. According to NCD-RisC data, in 2015, men had a higher agestandardized mean SBP than women in most countries. Men also had higher DBP and prevalence of raised blood pressure than women in most countries, except in sub-Saharan Africa and a few countries in Oceania and Asia, where the sex-specific pattern was reversed. The male-female differences in the age-standardized mean and prevalence were mainly owing to sex-specific differences before the age of 50 years. Men and women aged $\geq 50$ years had more similar mean SBP and DBP and prevalence of raised blood pressure, with countries divided into some with lower and others with higher blood pressure in men (FIG. 6). The male-female difference in blood pressure in 2015 was on average larger in high-income countries and those in Central and Eastern Europe than in countries in other regions.

Subnational patterns of blood pressure. Several studies have considered differences in blood pressure between rural and urban populations or in relation to socioeconomic status (SES). In high-income countries, blood pressure has consistently been reported to be higher in low-SES groups than in high-SES groups and higher in poorer and more rural areas of countries than in richer urban centres ${ }^{141-145}$. The observed decline in blood pressure in high-income countries benefited all SES groups; however, the inverse SES gradient has persisted for as long as data have been available ${ }^{146-153}$.

Data from studies on geographical and socioeconomic patterns of blood pressure and hypertension in low-income and middle-income countries are more mixed than in high-income nations $s^{7,142,154-165}$. A review of early data from Africa and Asia led to the conclusion that "there are communities, in whom blood pressure does not rise with age and in whom the problem of essential hypertension and its complications appears to be virtually non-existent. I must emphasize that in the vast majority of tropical communities blood pressure patterns are similar to those seen in the economically 
Raised blood pressure, men 2015

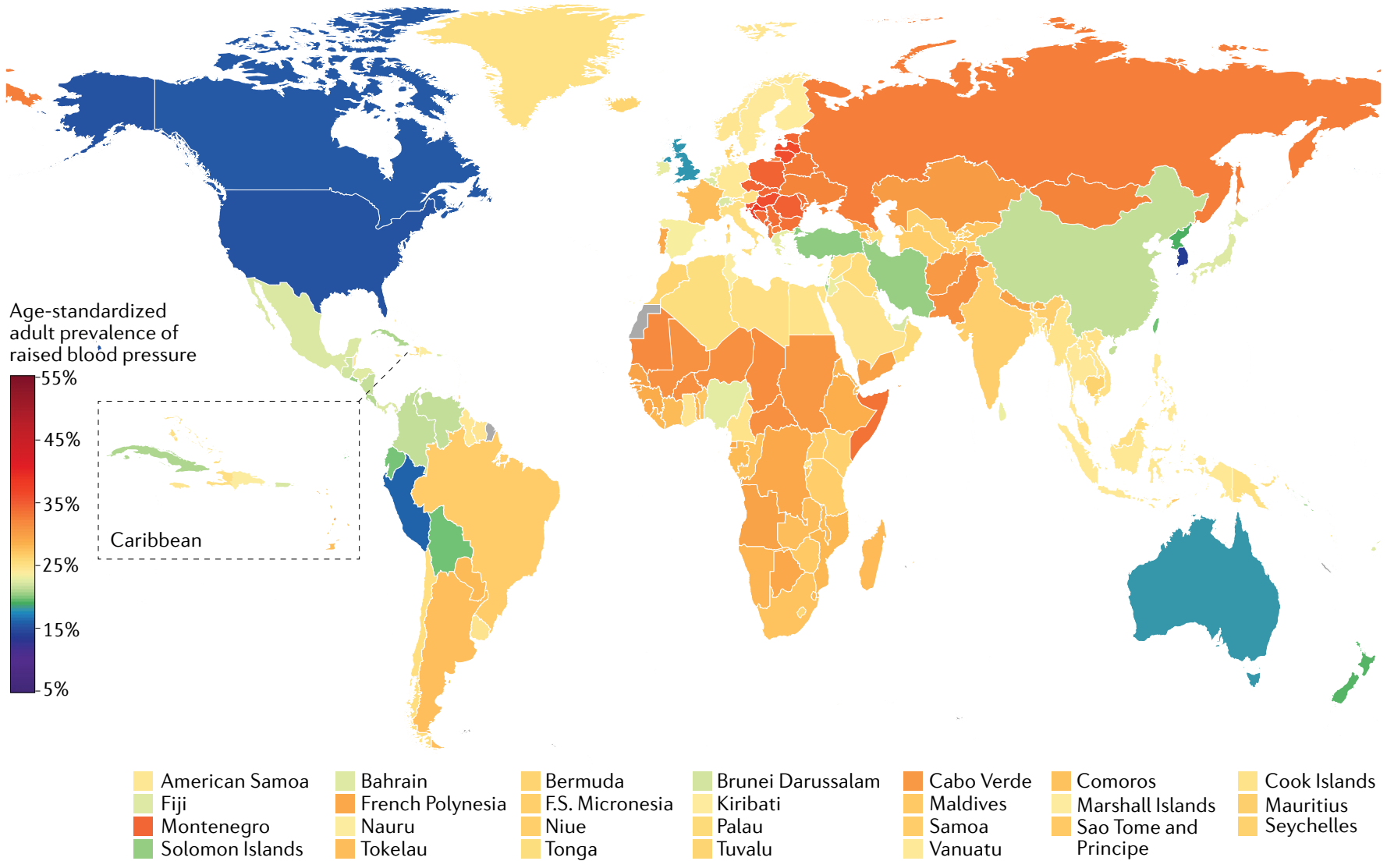

Raised blood pressure, women 2015

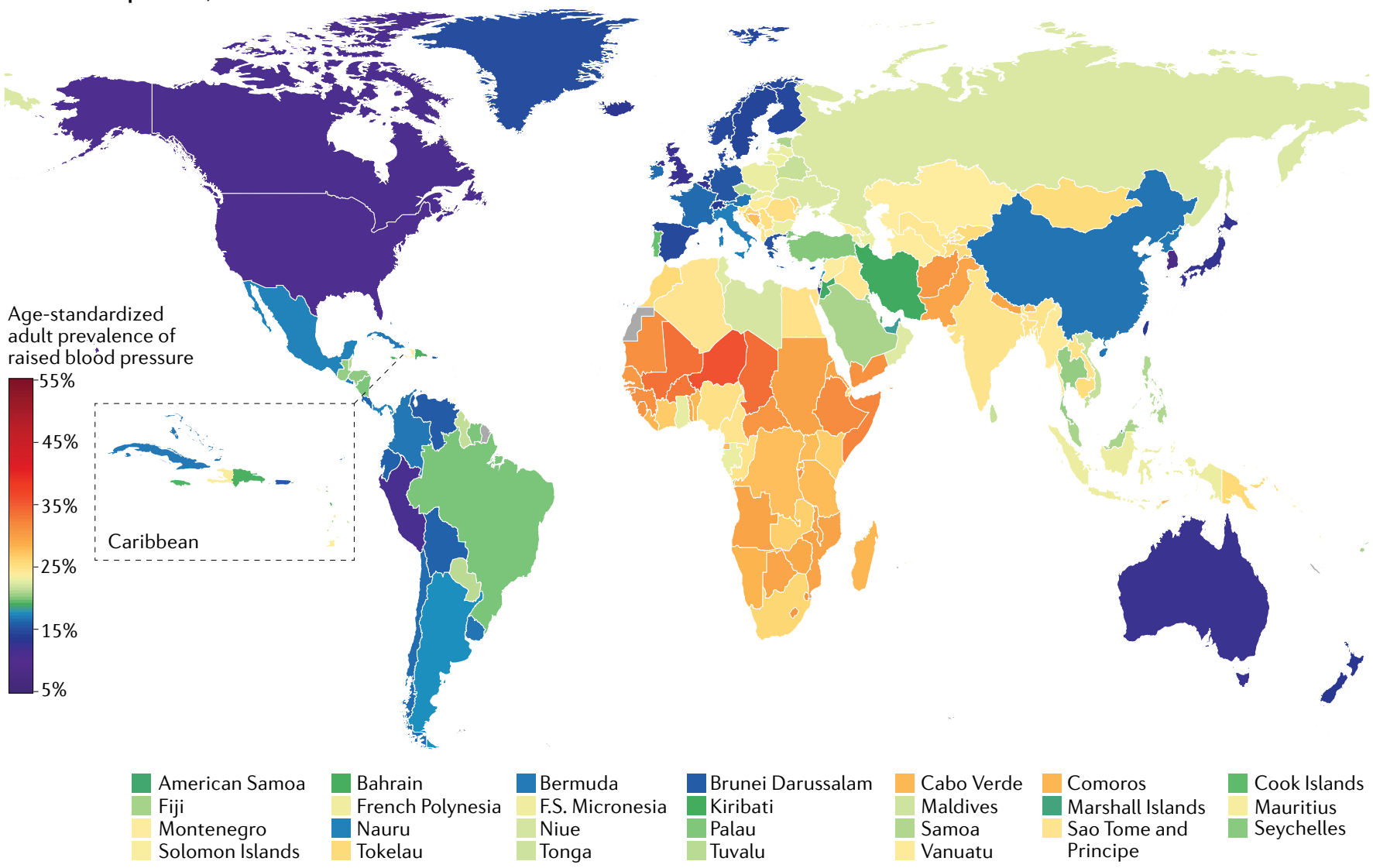


4 Fig. 4 | Worldwide prevalence of raised blood pressure. Age-standardized prevalence of raised blood pressure by country in 2015 (REF. ${ }^{102}$ ).

advanced countries of the world"166. Meta-analyses and re-analyses of health survey data have concluded that groups with lower SES have a higher prevalence of hypertension in countries across all income levels except those in Africa ${ }^{167,168}$. The multicentre PURE study ${ }^{73}$ also found that high-education groups have a lower prevalence of hypertension in all countries except those in low-income nations.

\section{Mortality}

A few studies have combined data on the population mean blood pressure with risk ratios from epidemiological studies to estimate the number of deaths attributable to high blood pressure ${ }^{11,169-172}$. The focus of these calculations was initially on CVDs and was subsequently extended to include chronic kidney disease ${ }^{11,171,172}$. According to data from these studies, an estimated 7.7-10.4 million annual deaths are attributable to elevated blood pressure levels ${ }^{11,172}$.

FIGURE 7 shows the number of deaths from CVDs and chronic kidney disease attributable to all levels of high blood pressure by region and cause of death. In 2015, an estimated 4.5 million deaths in men and 4.0 million deaths in women were attributable to SBP higher than the optimal level of $115 \mathrm{mmHg}, 88 \%$ of which were in low-income and middle-income regions. This figure represents an increase of 1.6 million and 0.9 million for men and women, respectively, compared with 1990 . The increase was a result of doubling of deaths attributable to high blood pressure in East, South and Southeast Asia and sub-Saharan Africa. By contrast, in high-income Western and Asia Pacific regions, the number of deaths attributable to high blood pressure declined by $20-30 \%$ despite a larger and older population. In relative terms, deaths from chronic kidney disease attributable to high blood pressure increased more than deaths from CVDs (FIG. 7).

\section{Prevention and management}

Non-pharmacological interventions. Successful control of hypertension should entail a comprehensive strategy of prevention at the individual and population levels, with the use of non-pharmacological interventions throughout the life course $\mathrm{1}^{1,103,173}$. Although a large number of studies have established risk factors for hypertension, fewer studies have evaluated the effectiveness of non-pharmacological interventions for hypertension prevention, especially in global or multi-country contexts. Studies that have evaluated the effectiveness of non-pharmacological interventions for hypertension prevention include some of the Lancet Series in $\mathrm{NCDs}^{174}$, the Disease Control Priorities study ${ }^{175}$, the Lancet Commission on Hypertension ${ }^{1}$, and the WHO Action Plan for the Prevention and Control of NCDs ${ }^{176}$. Prevention of hypertension is also addressed in some national and regional guidelines ${ }^{177-179}$. Effective interventions at the individual level include advice from physicians and nurses to reduce dietary sodium and increase the consumption of fruits and vegetables.
At the population level, several interventions and strategies are effective in reducing the risk of hypertension. Examples of effective population-based interventions include increasing the availability and affordability of fresh fruits and vegetables through pricing and targeted subsidies for low-income families, lowering the sodium content of packaged and prepared food and staples such as bread by influencing food reformulation and regulatory and voluntary mechanisms and making dietary salt substitutes readily available and accessible ${ }^{1,174-176,179}$. The success of these strategies requires active and sustained collaboration among global, regional, national and local governments, myriad government agencies, and health promotion and disease prevention experts ${ }^{179-181}$. Implementation research is needed to identify what individual and population-level interventions and strategies work best and can be sustained in each setting and any unintended consequences ${ }^{1,182}$. In particular, studies in low-income and middle-income countries are needed to identify and evaluate effective population-level interventions in settings with limited resources available to individuals, families and governments, and with limited infrastructure, and in different social contexts.

Pharmacological treatment. Progress in the pharmacological treatment of hypertension in the past 50 years is among the most remarkable in medicine. With hundreds of thousands of patients recruited into trials since the landmark VA Cooperative Study ${ }^{29}$, a wide portfolio now exists of cost-effective and safe pharmacological options to treat people with hypertension. The evidence is among the most robust in clinical medicine and supported by the largest number of outcome-based randomized clinical trials ${ }^{178}$. Systematic reviews and meta-analyses of trials have shown that a $10 \mathrm{mmHg}$ reduction in SBP or a $5 \mathrm{mmHg}$ reduction in DBP is associated with substantial reductions in all major cardiovascular events (about 40\% in heart failure, 35\% in stroke, $15 \%$ in coronary heart disease, $20 \%$ in cardiovascular mortality and $10 \%$ in all-cause mortality ${ }^{183}$. Importantly, these relative risk reductions are consistent across baseline levels of blood pressure and absolute disease risk and comorbidities ${ }^{4,7,33}$.

Many hypertension clinical guidelines exist worldwide, including the 2018 guidelines by the European Society of Cardiology and the European Society of Hypertension ${ }^{178}$ and the 2020 guidelines by the International Society of Hypertension ${ }^{184}$. Several national guidelines have been developed within the past 5 years, including guidelines from Canada ${ }^{177}$, China ${ }^{185}$, India ${ }^{186}$, Kenya ${ }^{187}$, the $\mathrm{UK}^{188}$ and the USA ${ }^{189}$. WHO is also working on its first hypertension clinical guideline, which is expected to be ready in 2021. Although guidelines can differ in certain features, such as the blood pressure threshold value required to start treatment or the target blood pressure for those on treatment, a clear consensus exists about the strong evidence for the effectiveness of four major classes of pharmacotherapies, including blockers of the renin-angiotensin-aldosterone system (RAAS), calcium channel blockers, $\beta$-blockers and thiazide or thiazide-like diuretics. Although specific indications exist for some of the pharmacological groups, such as $\beta$-blockers for patients with coronary artery 
Mean systolic blood pressure

a Per capita GDP

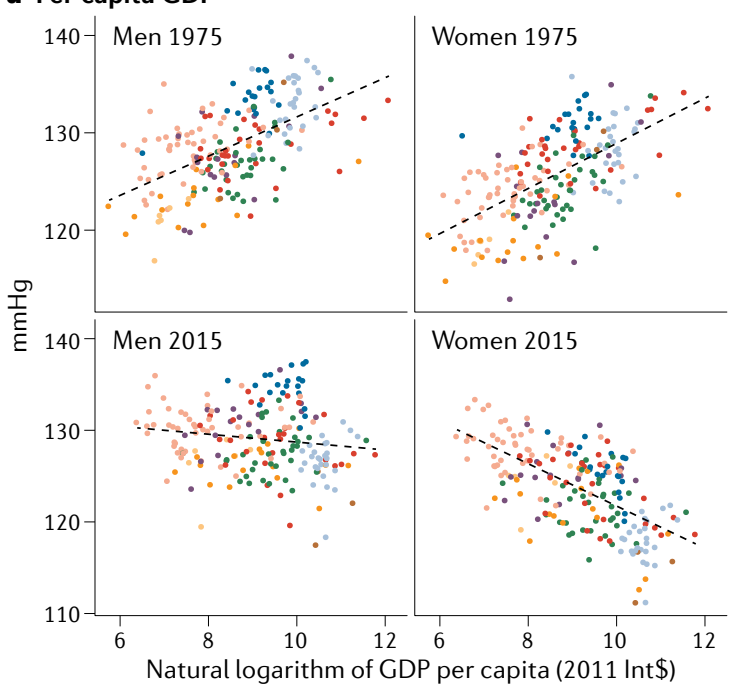

b Proportion of the population living in urban areas

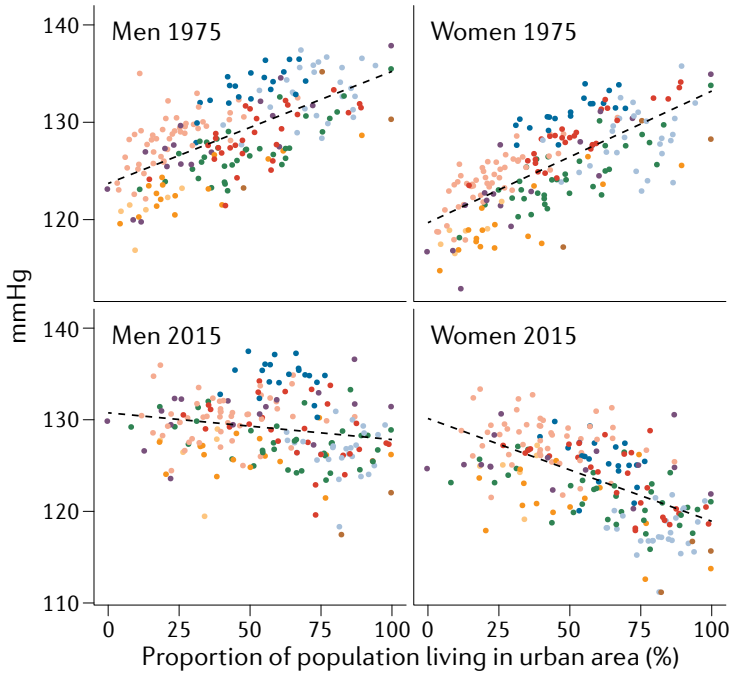

Mean diastolic blood pressure

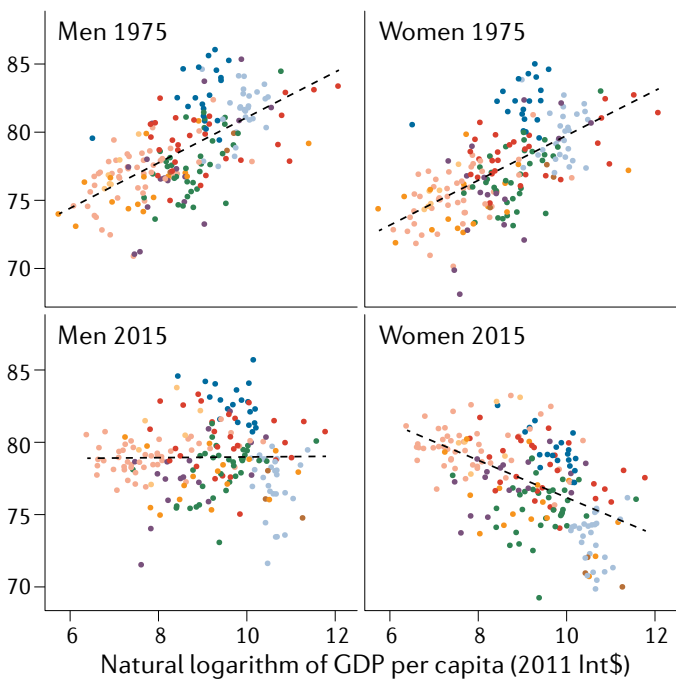

\section{c Mean BMI}
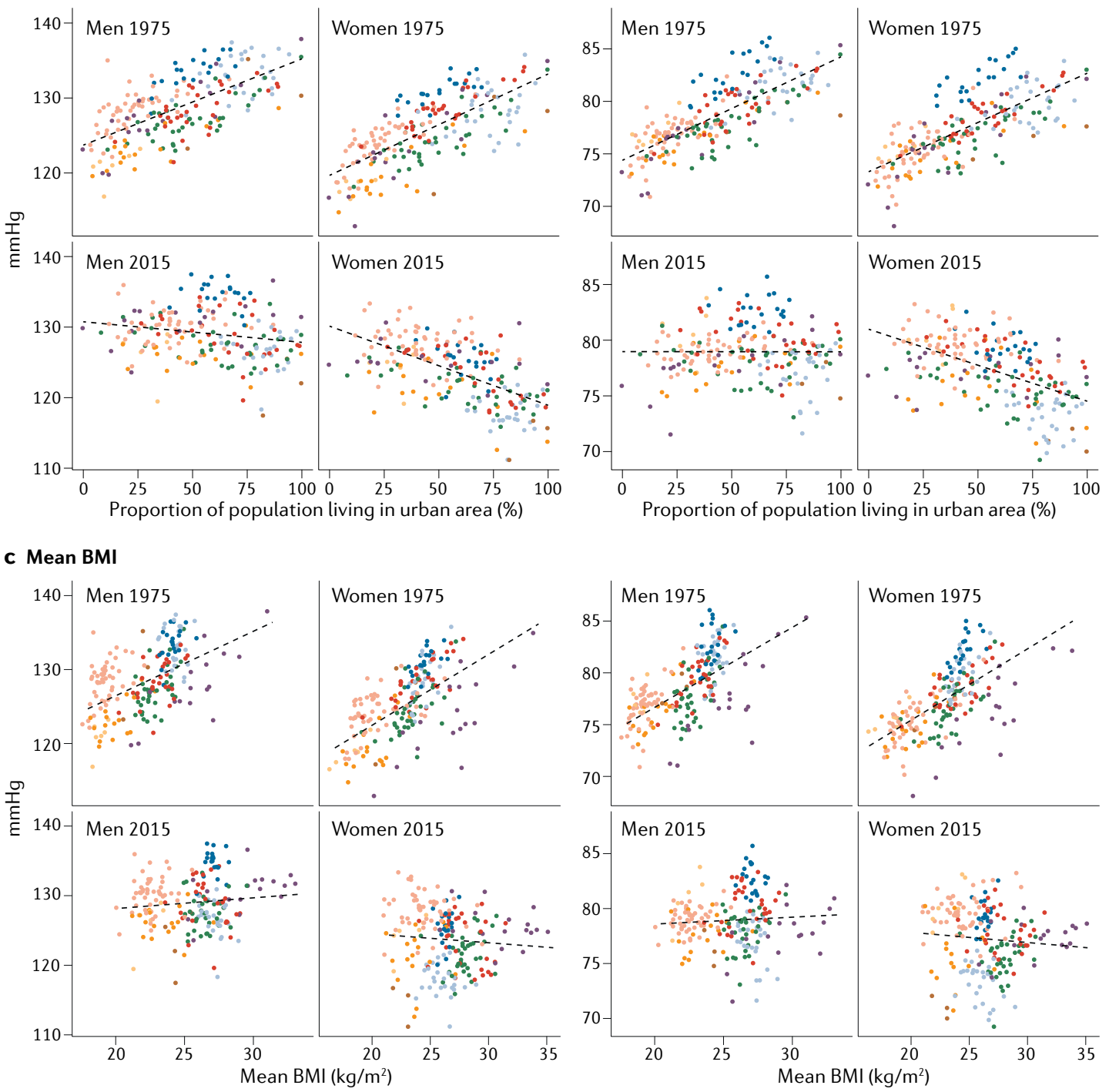

- Central and Eastern Europe East and Southeast Asia

- Central Asia, Middle East - High-income Asia Pacific and North Africa

- High-income Western Oceania Sub-Saharan - Latin America and South Asia Africa Caribbean 
Fig. 5 | Association between country characteristics and blood pressure.

a | Relationship between mean systolic and diastolic blood pressure and per capita gross domestic product (GDP) for 1975 and 2015. b | Relationship between mean systolic and diastolic blood pressure and the proportion of the population living in urban areas for 1975 and 2015. c| Relationship between mean systolic and diastolic blood pressure and mean BMI for 1975 and 2015. In 1975, mean systolic and diastolic blood pressure were positively correlated with GDP, the proportion of the population living in urban areas and mean BMI. In 2015, mean blood pressure was no longer correlated with these country characteristics for men and negatively correlated with GDP and the proportion of the population living in urban areas for women. Each point shows one country, coloured by region. which can be combined statistically into risk scores ${ }^{192}$. In addition to the content of guidelines, recognition of the importance of delivery approaches for successful guideline implementation has increased. Some of the effective implementation approaches include task shifting, electronic decision-support tools and simplification of guidelines ${ }^{193,194}$. The increasing recognition of the need to simplify guidelines has influenced global hypertension programmes, such as the programmes by the Resolve To Save Lives initiative and the Global Standardization of Hypertension Treatment Project, which have adopted simplified treatment protocols guided by local circumstances to improve compliance ${ }^{195,196}$. Finally, although antihypertensive treatment counts among the most remarkable achievements in clinical medicine, and now many antihypertensive drugs are cost-effective, safe and off-patent, the availability and affordability of antihypertensive drugs are limited, and their use is still low, as we discuss in the next section ${ }^{197}$.

Global variations in treatment. The extent to which patients with hypertension are treated and whether their blood pressure is lowered to levels below the threshold for hypertension (that is, controlled) varies substantially across countries. A regional hypertension programme by Kaiser Permanente Northern California and the nationwide Canadian Hypertension Education Program have achieved some of the best performances in hypertension control, with $70-90 \%$ of individuals with hypertension having their blood pressure controlled ${ }^{198,199}$. This achievement demonstrates that high levels of hypertension control are feasible through improving health-care provider and patient compliance with evidence-based tors such as lipid levels, diabetes mellitus and smoking, consider the overall cardiovascular risk of treatment recommendations. The overall risk can be estimated by considering age and other cardiovascular risk fac-

Systolic blood pressure

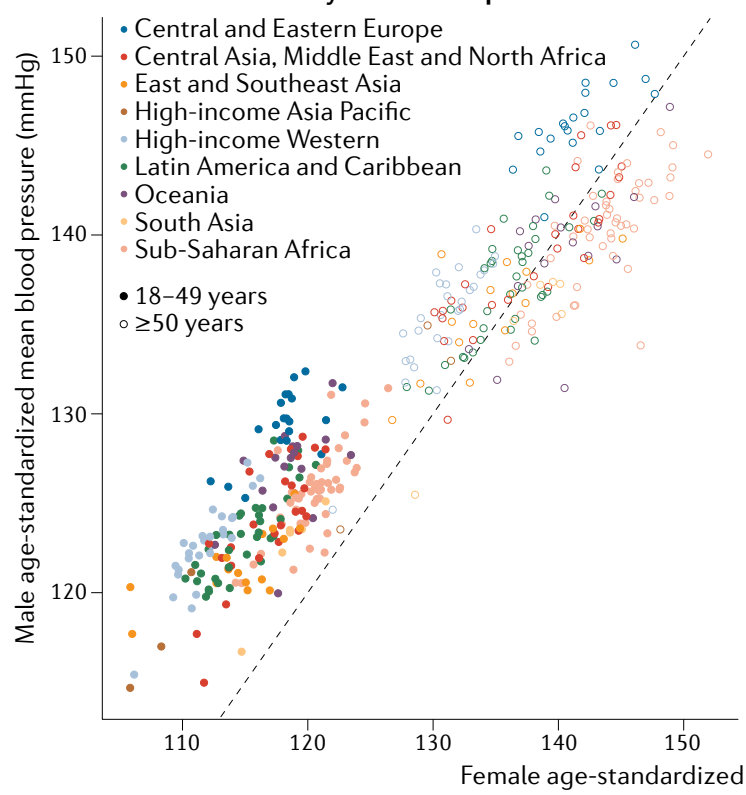

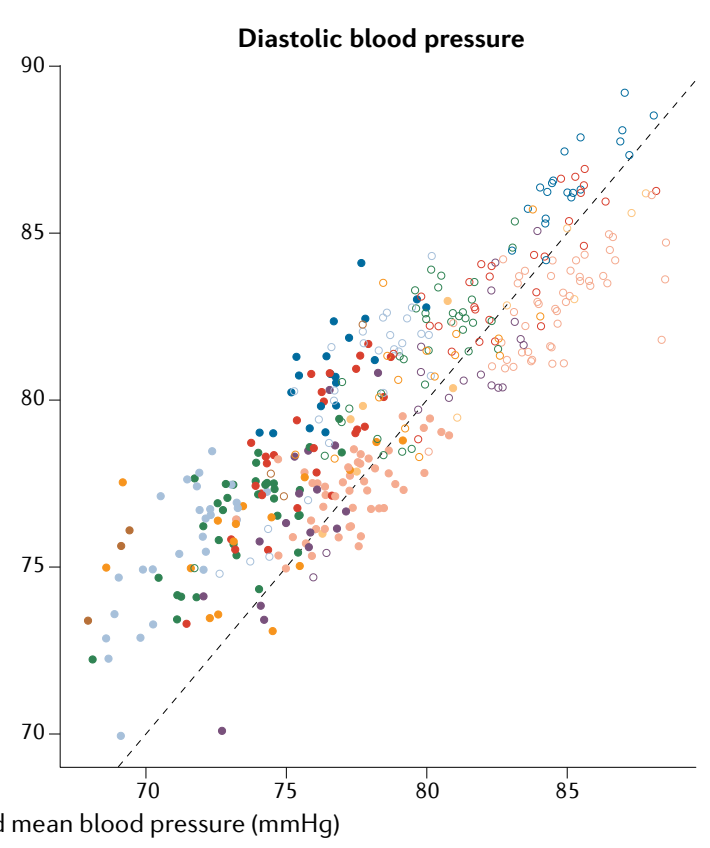

Fig. 6 | Comparison of female and male blood pressures. Comparison of female and male blood pressures in people aged $18-49$ years and $\geq 50$ years in 2015 . Each point shows one country, coloured by region. The interaction between sex and age group was significant $(P<0.0001$ for systolic and diastolic blood pressure) in an analysis of variance in a model with blood pressure as a dependent variable and sex, age group and their interaction as independent variables. Men aged 18-49 years have higher blood pressure levels than women of the same age in most countries, and men and women aged $\geq 50$ years have on average similar blood pressure levels. 
1990

Men

90

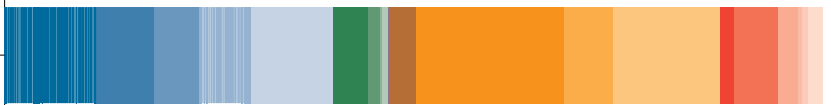

2015

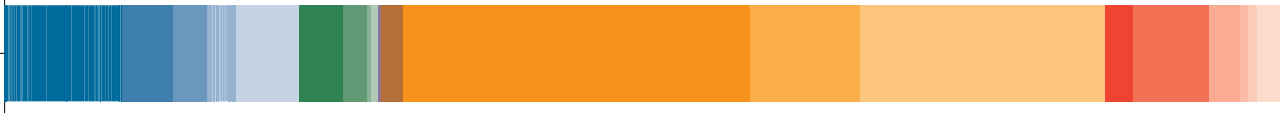

Women

1990

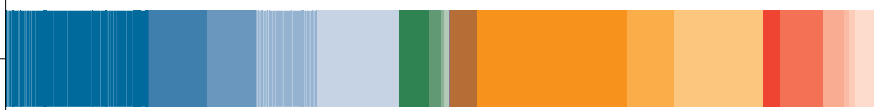

2015
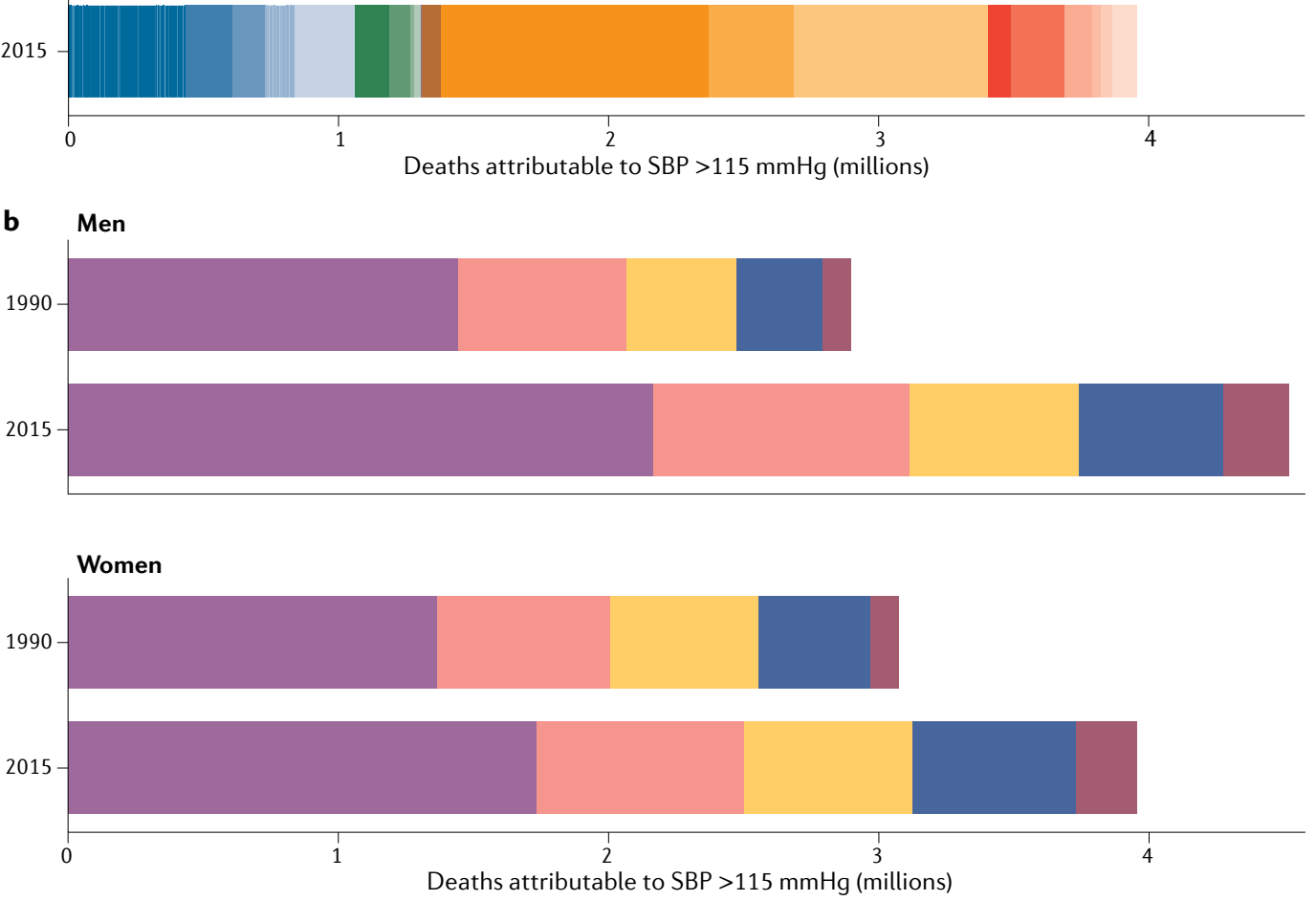

West Africa

Central Africa

Southern Africa

East Africa

Middle East and North Africa

Central Asia

South Asia

Southeast Asia

East Asia

High-income Asia Pacific

Melanesia

Polynesia and Micronesia

Caribbean

Andean Latin America

Central Latin America

Southern Latin America

High-income English-speaking

Northwestern Europe

Southwestern Europe

Central Europe

Eastern Europe

\section{Cause of death}

Ischaemic heart disease

Haemorrhagic stroke

Ischaemic stroke

Other cardiovascular diseases

Chronic kidney disease

Fig. 7 | Deaths attributable to high blood pressure. Deaths attributable to high systolic blood pressure (SBP) in 1990 and 2015, coloured by region (part a) and cause of death (part b).

guidelines, updating recommendations annually, establishing a hypertension registry, monitoring physician performance and providing feedback, implementing regular blood pressure measurements and single-pill combination therapy, tailored knowledge dissemination and national leadership ${ }^{198,200}$.

National coverage and effectiveness of hypertension treatment vary substantially. A 2019 study used national data from 44 low-income and middle-income countries and found that only $30 \%$ of people with hypertension are receiving pharmacological treatment and only $10 \%$ have their blood pressure controlled below the hypertension threshold level ${ }^{92}$. High-income countries generally perform better, but treatment and control rates in most countries are lower than those with high-quality hypertension programmes. Another 2019 study used national data on hypertension treatment from the $1970 \mathrm{~s}$ in 12 high-income countries ${ }^{95}$. The study showed that Canada, Germany, South Korea and the USA had the highest rates of awareness, treatment and control of hypertension, whereas Finland, Ireland, Japan and Spain had the lowest. Even in the best-performing countries, treatment coverage for hypertension was at most $80 \%$ and control rates were $<70 \%$, with treatment and control rates being as low as $40 \%$ and $20 \%$, respectively, in the worst-performing countries ${ }^{95}$. The study also found that hypertension treatment and control rates have plateaued since 2010 (REF. ${ }^{95}$ ). Another study used data from 90 countries worldwide and found that, between 2000 and 2010, the percentage of people with hypertension who were being treated increased both in high-income and in low-income and middle-income countries, but the gap between them widened ${ }^{98}$.

Some studies have identified factors that affect the treatment of hypertension. The implementation of universal health coverage, the extent of out-of-pocket spending for care and medicines, and the number and location of health facilities influence access to health-care. The extent of diagnosis and appropriate treatment of hypertension are influenced by the number of health personnel and mechanisms such as task sharing with non-physician health workers and well-developed 
clinical guidelines for hypertension management ${ }^{201,202}$. Well-developed supply chains ensure regular availability of antihypertensive medicine, which, together with their cost and the extent of the out-of-pocket payment, determine whether patients can obtain and afford the medicine ${ }^{197}$. In addition, mechanisms such as m-health (for example, text message reminders), home visits by community health workers and other community-based health promotion programmes improve patient adherence to treatment ${ }^{203-208}$. Similarly, the use of combination therapy improves both adherence to treatment and treatment effectiveness ${ }^{190,209,210}$. Evidence from trials supports the effectiveness of improving many of these factors, but macrosocial and macroeconomic factors, including insurance, procurement and personnel, affect how interventions can be scaled up regionally and nationally.

Information technology has brought new approaches to hypertension management. Telemedicine might help overcome physical barriers to accessing health care, including for remote and disparate populations and at times of restricted population mobility. However, the evidence from clinical trials is mixed on the effectiveness of telemedicine in improving blood pressure control ${ }^{211-213}$. Other approaches are emerging, including smartphonebased apps for self-management and tracking and wearable devices (for example, smartwatches) that measure blood pressure. Although these approaches look promising, the evidence is limited to support their effectiveness in improving blood pressure control ${ }^{214-216}$. By providing remote access to health care, these approaches might partly overcome the obstacles posed by limited health infrastructure for hypertension control in low-income and middle-income countries. Conversely, they might create new barriers for some caused by the increased demand for new technology that might be available only to those with higher income and education. Therefore, a need exists to conduct implementation research on these approaches to identify the populations and contexts in which they work, and to determine how they work and their effects on inequalities.

Global hypertension initiatives. The public health importance of hypertension is recognized in several global initiatives. Global Hearts, led by WHO, includes

\section{Table 1 | Features of global initiatives and programmes for hypertension treatment}

\begin{tabular}{|c|c|c|}
\hline $\begin{array}{l}\text { Initiative or } \\
\text { programme }\end{array}$ & $\begin{array}{l}\text { Target } \\
\text { regions }\end{array}$ & Key areas of action \\
\hline $\begin{array}{l}\text { Global Hearts } \\
\text { (WHO) }\end{array}$ & NA & $\begin{array}{l}\text { HEARTS (six technical packages for the prevention and control of cardiovascular } \\
\text { disease): training health-care workers to counsel on behavioural risk factors and } \\
\text { healthy lifestyles; simple, standardized and evidence-based treatment protocols } \\
\text { for hypertension and diabetes mellitus; ensuring access to essential medicines } \\
\text { and technology; risk-based approach to the management of cardiovascular } \\
\text { disease, including country-specific risk charts; implementing team-based care } \\
\text { and task shifting; and improved monitoring system with standardized indicators } \\
\text { (for example, hypertension control rate) and data collection tools }\end{array}$ \\
\hline $\begin{array}{l}\text { WHF Hypertension } \\
\text { Roadmap }\end{array}$ & NA & $\begin{array}{l}\text { Opportunistic screening; promoting use of inexpensive, good-quality generic } \\
\text { medications for hypertension; education on adherence to lifestyle modification } \\
\text { and medication use }\end{array}$ \\
\hline $\begin{array}{l}\text { Pan-African Society } \\
\text { of Cardiology } \\
\text { Roadmap }\end{array}$ & $\begin{array}{l}\text { Sub-Saharan } \\
\text { Africa }\end{array}$ & $\begin{array}{l}\text { A ten-point action plan for African ministries of health, including: creating or } \\
\text { adopting simple and practical clinical evidence-based hypertension management } \\
\text { guidelines; annual monitoring and report of the detection, treatment and control } \\
\text { rates of hypertension, with a clear target for improvement by } 2025 \text {, with use of the } \\
\text { WHO STEPwise approach to surveillance; integrating hypertension management } \\
\text { within existing health services such as disease-specific vertical programmes } \\
\text { (for example, HIV and tuberculosis); task-sharing with trained community health } \\
\text { workers; and ensuring availability of essential equipment and medicines }\end{array}$ \\
\hline $\begin{array}{l}\text { Resolve To Save } \\
\text { Lives }\end{array}$ & $\begin{array}{l}\text { China, India, } \\
\text { Thailand }\end{array}$ & $\begin{array}{l}\text { Practical treatment protocols with specific medications, dosages and steps } \\
\text { to take if blood pressure is not controlled; adopting community-based care and } \\
\text { task sharing; ensuring supply of medications; adopting easy-to-take medicine } \\
\text { regimens, using free or low-cost medications and follow-up visits, and making } \\
\text { blood pressure monitoring readily available; and leveraging technology to } \\
\text { develop information systems that allow for continuous, real-time improvement }\end{array}$ \\
\hline $\begin{array}{l}\text { Global } \\
\text { Standardization } \\
\text { of Hypertension } \\
\text { Treatment Project }\end{array}$ & $\begin{array}{l}\text { Barbados, } \\
\text { Malawi }\end{array}$ & $\begin{array}{l}\text { Using nationally relevant, evidence-based and implementable treatment } \\
\text { protocols that are endorsed by key stakeholders; identifying a core set of widely } \\
\text { available medications that are safe and effective; ensuring the quality, safety } \\
\text { and consistent supply of the core set of medications; developing hypertension } \\
\text { registries and monitoring targets (for example, blood pressure control) within a } \\
\text { care system or programme to evaluate the efficacy of the system or programme } \\
\text { and make adjustments accordingly; empowering patients by involving them in } \\
\text { decisions related to their treatment, creating a physician-patient relationship on } \\
\text { the basis of mutual respect, and utilizing educational materials and peer-support } \\
\text { groups to improve the knowledge, attitude and adherence to treatment of } \\
\text { the patients; use of team-based care that coordinates care delivery within the } \\
\text { team (task sharing) and ensures continuity of care; and use of community-based } \\
\text { settings for services such as blood pressure checks and education and engaging } \\
\text { community partners (for example, civil society organizations and media) }\end{array}$ \\
\hline
\end{tabular}


two specific components related to hypertension; the SHAKE package (salt reduction) and the HEARTS technical package (strengthening the management of CVDs in primary health care $)^{217}$. The World Heart Federation Hypertension Roadmap, and its regional adaptations such as the one developed by the Pan-African Society of Cardiology, aims to provide a framework for countries and regions to implement policy and health system solutions for hypertension control ${ }^{218,219}$. The Resolve To Save Lives initiative aims to prevent 100 million deaths globally and has two hypertension-related components (salt reduction and hypertension control ${ }^{220}$. The global importance of hypertension is also recognized because hypertension treatment coverage is considered a tracer indicator in the WHO universal health coverage index ${ }^{221}$. The key features of global hypertension initiatives and programmes are summarized in TABLE 1.

Hypertension and the COVID-19 pandemic. Hypertension has emerged as a common comorbidity in patients hospitalized with COVID-19 (REFS ${ }^{222-230}$ ). Studies in China, Italy, the UK and the USA found a strong association between pre-existing hypertension and disease severity and mortality. However, findings were mixed after accounting for age and other comorbidities and risk factors, particularly obesity and diabetes, which often co-occur with hypertension ${ }^{222,223,230-237}$. Therefore, at the time of this Review, insufficient evidence exists to establish hypertension or high blood pressure as a risk factor for hospitalization with, or prognosis of, COVID-19 independent of age and other conditions.

Severe acute respiratory syndrome coronavirus 2 (SARS-CoV-2) binds to angiotensin-converting enzyme 2 receptors to gain access to cells ${ }^{238}$. Therefore, concerns existed about the safety of RAAS inhibitors for patients with COVID-19 (REF. ${ }^{239}$ ). However, a growing body of evidence has emerged to allay this concern ${ }^{231,240,241}$, and clinical groups have recommended the continued use of RAAS inhibitors in these patients ${ }^{242-248}$. In addition, studies have shown a potential protective effect of RAAS inhibitors in patients with COVID-19 with or without hypertension ${ }^{249-252}$, but data are limited beyond recommending that patients receiving RAAS inhibitors should continue with their medication as usual.

At the time of this Review, the COVID-19 pandemic has also had an important indirect effect on hypertension and $\mathrm{CVDs}^{243,253,254}$. Elective patient care and routine contact with health-care services, including hypertension care, has plummeted since the outbreak, especially where national or local lockdowns have been implemented ${ }^{255-258}$. The reduced contact with health-care services might delay the diagnosis of hypertension and disrupt the treatment of hypertension. A WHO survey revealed that $53 \%$ of countries have reported disruptions in hypertension management ${ }^{256}$, but the precise effect of this disruption remains unknown. The COVID-19 pandemic might also affect social networks and interactions, physical activity, smoking, mental stress, alcohol use and $\operatorname{diet}^{259,260}$, all of which influence hypertension directly or indirectly. Together with other disruptions in care, these issues might have already contributed to excess deaths beyond those caused by COVID-19 directly ${ }^{261}$.

What long-term effect the COVID-19 pandemic will have on hypertension management remains uncertain. For example, there might be an increased uptake of telemedicine or remote consultation with general practitioners ${ }^{243,253}$. In the short term, efforts should be focused on ensuring that all social groups, particularly poor and vulnerable groups, have opportunities and support to access healthy foods and to have outdoor time, and that preventive and treatment care continues to be available.

\section{Conclusions}

This Review demonstrates that hypertension has always been present in low-income populations throughout the world to varying degrees. After decades of decline in high-income countries and an increase in some low-income and middle-income regions, blood pressure levels are now much higher in lower-income countries, especially in sub-Saharan Africa and South Asia, and in Central and Eastern Europe. Consequently, now $88 \%$ of the mortality attributable to high blood pressure is outside high-income regions. We have also found that the evidence on whether blood pressure and hypertension are higher in rural or urban populations is equivocal.

The reasons for the massive declines in blood pressure in high-income countries are probably multifaceted and include both general economic and infrastructural development and specific actions in the health systems towards prevention and treatment ${ }^{71,122}$. Although overall economic and health development over the coming decades might replicate these achievements elsewhere, the large and globally inequitable burden of high blood pressure should motivate the use of the personal and population-based interventions reviewed here so that rising trends are reversed and declines are accelerated.

Published online 28 May 2021
1. Olsen, M. H. et al. A call to action and a lifecourse strategy to address the global burden of raised blood pressure on current and future generations: the Lancet Commission on hypertension. Lancet 388 , 2665-2712 (2016)

2. Xie, X. et al. Effects of intensive blood pressure lowering on cardiovascular and renal outcomes: updated systematic review and meta-analysis. Lancet 387, 435-443 (2016).

3. Bundy, J. D. et al. Systolic blood pressure reduction and risk of cardiovascular disease and mortality: a systematic review and network meta-analysis. JAMA Cardiol. 2, 775-781 (2017).

4. Ettehad, D. et al. Blood pressure lowering for prevention of cardiovascular disease and death a systematic review and meta-analysis. Lancet 387 957-967 (2016).

5. Lewington, S. et al. Age-specific relevance of usua blood pressure to vascular mortality: a meta-analysis of individual data for one million adults in 61 prospective studies Lancet 360, 1903-1913 (2002).

6. Lawes, C. M. M. et al. Blood pressure and cardiovascular disease in the Asia Pacific region. J. Hypertens. 21, 707-716 (2003).

7. Czernichow, S. et al. The effects of blood pressure reduction and of different blood pressure-lowering regimens on major cardiovascular events according to baseline blood pressure: meta-analysis of randomized trials. J. Hypertens. 29, 4-16 (2011).
8. Singh, G. M. et al. The age-specific quantitative effects of metabolic risk factors on cardiovascular diseases and diabetes: a pooled analysis. PLOS ONE 8, e65174 (2013).

9. Kennelly, S. P., Lawlor, B. A. \& Kenny, R. A Blood pressure and dementia - a comprehensive review. Ther. Adv. Neurol. Disord. 2, 241-260 (2009).

10. Sharp, S. I. et al. Hypertension is a potential risk factor for vascular dementia: systematic review. Int. J. Geriatr. Psychiatry 26, 661-669 (2011).

11. Global Burden of Metabolic Risk Factors for Chronic Diseases Collaboration. Cardiovascular disease, chronic kidney disease, and diabetes mortality burden 
of cardiometabolic risk factors from 1980 to 2010: a comparative risk assessment. Lancet Diabetes Endocrinol. 2, 634-647 (2014).

12. Kontis, V. et al. Contribution of six risk factors to achieving the $25 \times 25$ non-communicable disease mortality reduction target: a modelling study. Lancet 384, 427-437 (2014).

13. Kontis, V. et al. Regional contributions of six preventable risk factors to achieving the $25 \times 25$ non-communicable disease mortality reduction target: a modelling study. Lancet Glob. Health 3, e746-e757 (2015).

14. World Health Organization. NCD global monitoring framework (WHO, 2013)

15. Ni, M. The Yellow Emperor's Classic of Medicine: A New Translation of the Neijing Suwen with Commentary (Shambhala, 1995).

16. Freis, E. D. in Hypertension: Pathophysiology, Diagnosis and Management Ch. 164 (eds Laragh, J. H \& Brenner, B. M.) 2741-2751 (Raven, 1995).

17. Beevers, D. G. \& Robertson, J. I. S. in Comprehensive hypertension (eds Lip, G. Y. H. \& Hall, J. E.) 3-20 (Elsevier, 2007).

18. Esunge, P. M. From blood pressure to hypertension: the history of research. J. R. Soc. Med. 84, 621 (1991).

19. Ghasemzadeh, N. \& Zafari, A. M. A brief journey into the history of the arterial pulse. Cardiol. Res. Pract. 2011, 164832 (2011)

20. Aird, W. C. Discovery of the cardiovascular system from Galen to William Harvey. J. Thromb. Haemost. 9 (Suppl 1), 118-129 (2011).

21. Cameron, J. S. \& Hicks, J. Frederick Akbar Mahomed and his role in the description of hypertension at Guy's Hospital. Kidney Int. 49, 1488-1506 (1996).

22. Booth, J. A short history of blood pressure measurement. Proc. R. Soc. Med. 70, 793-799 (1977).

23. O'Brien, E. $\&$ Fitzgerald, D. The history of blood pressure measurement. J. Hum. Hypertens. 8, 73-84 (1994).

24. Fisher, J. W. The diagnostic value of the sphygmomanometer in examinations for life insurance. JAMA LXIII, 1752-1754 (1914).

25. Tzoulaki, I., Elliott, P., Kontis, V. \& Ezzati, M Worldwide exposures to cardiovascular risk factors and associated health effects: current knowledge and data gaps. Circulation 133, 2314-2333 (2016).

26. Kotchen, T. A. Historical trends and milestones in hypertension research: a model of the process of translational research. Hypertension 58, 522-538 (2011).

27. Kannel, W. B., Dawber, T. R., Kagan, A., Revotskie, N. $\&$ Stokes, J., 3rd. Factors of risk in the development of coronary heart disease-six year follow-up experience. The Framingham Study. Ann. Intern. Med. 55, 33-50 (1961).

28. Vasan, R. S. et al. Impact of high-normal blood pressure on the risk of cardiovascular disease. N. Engl. J. Med. 345, 1291-1297 (2001).

29. [No authors listed]. Effects of treatment on morbidity in hypertension. Results in patients with diastolic blood pressures averaging 115 through $129 \mathrm{~mm} \mathrm{Hg}$. JAMA 202, 1028-1034 (1967).

30. [No authors listed]. Effects of treatment on morbidity in hypertension. II. Results in patients with diastolic blood pressure averaging 90 through $114 \mathrm{~mm} \mathrm{Hg}$ JAMA 213, 1143-1152 (1970).

31. Stamler, J., Stamler, R. \& Neaton, J. D. Blood pressure, systolic and diastolic, and cardiovascular risks. US population data. Arch. Intern. Med. 153 598-615 (1993)

32. Turnbull, F. et al. Effects of different blood pressurelowering regimens on major cardiovascular events in individuals with and without diabetes mellitus: results of prospectively designed overviews of randomized trials. Arch. Intern. Med. 165, 1410-1419 (2005)

33. Blood Pressure Lowering Treatment Trialists Collaboration. Blood pressure-lowering treatment based on cardiovascular risk: a meta-analysis of individual patient data. Lancet 384, 591-598 (2014).

34. Karmali, K. N. et al. Blood pressure-lowering treatment strategies based on cardiovascular risk versus blood pressure: a meta-analysis of individual participant data. PLoS Med. 15, e 1002538 (2018)

35. SPRINT Research Group. et al. A randomized trial of intensive versus standard blood-pressure control. N. Engl. J. Med. 373, 2103-2116 (2015).

36. Brouwer, T. F. et al. Intensive blood pressure lowering in patients with and patients without type 2 diabetes: a pooled analysis from two randomized trials. Diabetes Care 41, 1142-1148 (2018).

37. Verdecchia, P., Angeli, F., Gentile, G. \& Reboldi, G More versus less intensive blood pressure-lowering strategy: cumulative evidence and trial sequential analysis. Hypertension 68, 642-653 (2016).

38. Wallner, A., Hirz, A., Schober, E., Harbich, H. \& Waldhoer, T. Evolution of cardiovascular risk factors among 18-year-old males in Austria between 1986 and 2005. Wien. Klin. Wochenschr. 122, 152-158 (2010).

39. Ulmer, H., Kelleher, C. C., Fitz-Simon, N., Diem, C $£$ Concin, H. Secular trends in cardiovascular risk factors: an age-period cohort analysis of 698,954 health examinations in 181,350 Austrian men and women. J. Intern. Med. 261, 566-576 (2007)

40. Joossens, J. V. \& Kesteloot, H. Trends in systolic blood pressure, 24-hour sodium excretion, and stroke mortality in the elderly in Belgium. Am. J. Med. 90 , 5S-11S (1991).

41. McAlister, F. A. et al. Changes in the rates of awareness, treatment and control of hypertension in Canada over the past two decades. CMAJ 183 1007-1013 (2011)

42. Andersen, U. O. \& Jensen, G. Decreasing population blood pressure: 15 years of follow-up in the Copenhagen City Heart Study (CCHS). Blood Press. 13, 176-182 (2004)

43. Borodulin, K. et al. Forty-year trends in cardiovascular risk factors in Finland. Eur. J. Public. Health 25 539-546 (2015).

44. Nuotio, J. et al Cardiovascular risk factors in 2011 and secular trends since 2007: the Cardiovascular Risk in Young Finns Study. Scand. J. Public Health $\mathbf{4 2}$ 563-571 (2014)

45. Heinemann, L., Barth, W. \& Hoffmeister, H. Trend of cardiovascular risk factors in the East German population 1968-1992. J. Clin. Epidemiol. 48 787-795 (1995)

46. Di Lonardo, A., Donfrancesco, C., Palmieri, L. Vanuzzo, D. \& Giampaoli, S. Time trends of high blood pressure prevalence, awareness and contro in the Italian general population: surveys of the National Institute of Health. High Blood Press. Cardiovasc. Prev. 24, 193-200 (2017).

47. Ueshima, H., Tatara, K., Asakura, S. \& Okamoto, M Declining trends in blood pressure level and the prevalence of hypertension, and changes in related factors in Japan, 1956-1980. J. Chronic Dis. 40, 137-147 (1987)

48. Miura, K. Epidemiology and prevention of hypertension in Japanese: how could Japan get longevity? EPMA J. 2, 59-64 (2011).

49. Hopstock, L. A. et al. Longitudinal and secular trends in blood pressure among women and men in birth cohorts born between 1905 and 1977: the Troms $\varnothing$ Study 1979 to 2008. Hypertension 66, 496-501 (2015).

50. Pereira, M. et al. Trends in hypertension prevalence (1990-2005) and mean blood pressure (1975-2005) in Portugal: a systematic review. Blood Press. 21 220-226 (2012).

51. Bjorkelund, C. et al. Secular trends in cardiovascular risk factors with a 36-year perspective: observations from 38- and 50-year-olds in the Population Study of Women in Gothenburg. Scand. J. Prim. Health Care 26, 140-146 (2008)

52. Rosengren, A. et al. Secular changes in cardiovascular risk factors over 30 years in Swedish men aged 50: the study of men born in 1913,1923, 1933 and 1943. J. Intern. Med. 247, 111-118 (2000).

53. Falaschetti, E., Mindell, J., Knott, C. \& Poulter, N. Hypertension management in England: a serial cross-sectional study from 1994 to 2011. Lancet 383, 1912-1919 (2014)

54. Drizd, T., Dannenberg, A. L. \& Engel, A. Blood pressure levels in persons 18-74 years of age in 1976-80, and trends in blood pressure from 1960 to 1980 in the United States. Vital. Health Stat. 11 1-68 (1986)

55. Kumanyika, S. K., Landis, J. R., Matthews-Cook, Y. L., Almy, S. L. \& Boehmer, S. J. Systolic blood pressure trends in US adults between 1960 and 1980: influence of antihypertensive drug therapy. $\mathrm{Am}$. $\mathrm{J}$. Epidemiol. 148, 528-538 (1998).

56. Burt, V. L. et al. Trends in the prevalence, awareness, treatment, and control of hypertension in the adult US population. Data from the health examination surveys, 1960 to 1991 . Hypertension 26, 60-69 (1995).

57. Egan, B. M., Zhao, Y. \& Axon, R. N. US trends in prevalence, awareness, treatment, and control of hypertension, 1988-2008. JAMA 303, 2043-2050 (2010).

58. Goff, D. C., Gillespie, C., Howard, G. \& Labarthe, D. R. Is the obesity epidemic reversing favorable trends in blood pressure? Evidence from cohorts born between 1890 and 1990 in the United States. Ann. Epidemiol. 22, 554-561 (2012).

59. Bromfield, S. G. et al. Trends in hypertension prevalence, awareness, treatment, and control among US adults 80 years and older, 1988-2010. J. Clin. Hypertens. 16, 270-276 (2014).

60. Cifkova, R. et al. Longitudinal trends in cardiovascular mortality and blood pressure levels, prevalence, awareness, treatment, and control of hypertension in the Czech population from 1985 to 2007/2008. J. Hypertens. 28, 2196-2203 (2010).

61. Heiniger, S., Viswanathan, B., Gedeon, J., Paccaud, F. $\Sigma$ Bovet, P. Trends in prevalence, awareness, treatment and control of high blood pressure in the Seychelles between 1989 and 2013. J. Hypertens. 35, 1465-1473 (2017).

62. Diaz, A. \& Ferrante, D. Trends in prevalence of hypertension in Argentina in the last 25 years: a systematic review of observational studies. Rev. Panam. Salud Publica 38, 496-503 (2015).

63. Guo, J. et al. The dynamics of hypertension prevalence, awareness, treatment, control and associated factors in Chinese adults: results from CHNS 1991-2011. J. Hypertens. 33, 1688-1696 (2015).

64. Bosu, W. K. Epidemic of hypertension in Ghana: a systematic review. BMC Public Health 10, 418 (2010).

65. Gupta, R. Trends in hypertension epidemiology in India. J. Hum. Hypertens. 18, 73-78 (2004).

66. Ogah, O. S. et al. Blood pressure, prevalence of hypertension and hypertension related complications in Nigerian Africans: a review. World J. Cardiol. 4, 327-340 (2012)

67. Zerba, K. E., Friedlaender, J. S. \& Sing, C. F. Heterogeneity of the blood pressure distribution among Solomon Islands societies with increasing acculturation. Am. J. Phys. Anthropol. 81, 493-511 (1990).

68. Lanti, M. et al. Long-term trends in major cardiovascular risk factors in cohorts of aging men in the European cohorts of the Seven Countries Study. Aging Clin. Exp. Res. 17, 306-315 (2005).

69. [No authors listed]. Intersalt: an international study of electrolyte excretion and blood pressure. Results for 24 hour urinary sodium and potassium excretion. Intersalt Cooperative Research Group. BMJ 297 319-328 (1988).

70. Evans, A. et al. Trends in coronary risk factors in the WHO MONICA project. Int. J. Epidemiol. 30 (Suppl 1), 35-40 (2001).

71. Tunstall-Pedoe, H., Connaghan, J., Woodward, M., Tolonen, H. \& Kuulasmaa, K. Pattern of declining blood pressure across replicate population surveys of the WHO MONICA project, mid-1980s to mid-1990s, and the role of medication. BMJ 332, 629-635 (2006).

72. Antikainen, R. L. et al. Trends in the prevalence, awareness, treatment and control of hypertension: the WHO MONICA Project. Eur. J. Cardiovasc. Prev. Rehabil. 13, 13-29 (2006).

73. Chow, C. K. et al. Prevalence, awareness, treatment, and control of hypertension in rural and urban communities in high-, middle-, and low-income countries. JAMA 310, 959-968 (2013)

74. Basu, S. \& Millett, C. Social epidemiology of hypertension in middle-income countries: determinants of prevalence, diagnosis, treatment, and control in the WHO SAGE study. Hypertension 62, 18-26 (2013).

75. Lloyd-Sherlock, P., Beard, J., Minicuci, N., Ebrahim, S $\S$ Chatterji, S. Hypertension among older adults in low- and middle-income countries: prevalence, awareness and control. Int. J. Epidemiol. 43 116-128 (2014).

76. Rubinstein, A. L. et al. Prevalence, awareness, treatment, and control of hypertension in the Southern Cone of Latin America. Am. J. Hypertens. 29, 1343-1352 (2016).

77. Whelton, P. K., He, J. \& Muntner, P. Prevalence, awareness, treatment and control of hypertension in North America, North Africa and Asia. J. Hum. Hypertens. 18, 545-551 (2004).

78. Hernandez-Hernandez, R., Armas-Padilla, M. C., Armas-Hernandez, M. J. \& Velasco, M. Hypertension and cardiovascular health in Venezuela and Latin American countries. J. Hum. Hypertens. 14 (Suppl 1), 2-5 (2000). 
79. Sozmen, K. et al. Cardiovascular risk factor trends in the Eastern Mediterranean region: evidence from four countries is alarming. Int. J. Public. Health 60 (Suppl 1), 3-11 (2015).

80. Xi, B. et al. Recent blood pressure trends in adolescents from China, Korea, Seychelles and the United States of America, 1997-2012. J. Hypertens. 34, 1948-1958 (2016)

81. Joffres, M. et al. Hypertension prevalence, awareness, treatment and control in national surveys from England, the USA and Canada, and correlation with stroke and ischaemic heart disease mortality: a cross-sectional study. BMJ Open 3, e003423 (2013).

82. Motlagh, B., O’Donnell, M. \& Yusuf, S. Prevalence of cardiovascular risk factors in the Middle East: a systematic review. Eur. J. Cardiovasc. Prev. Rehabil. 16, 268-280 (2009)

83. Adeloye, D. \& Basquill, C. Estimating the prevalence and awareness rates of hypertension in Africa: a systematic analysis. PLOS ONE 9, e104300 (2014).

84. Ogah, O. S. \& Rayner, B. L. Recent advances in hypertension in sub-Saharan Africa. Heart 99 , 1390-1397 (2013)

85. Ataklte, F. et al. Burden of undiagnosed hypertension in sub-Saharan Africa: a systematic review and meta-analysis. Hypertension 65, 291-298 (2015).

86. Burroughs Pena, M. S., Mendes Abdala, C. V. Silva, L. C. \& Ordunez, P. Usefulness for surveillance of hypertension prevalence studies in Latin America and the Caribbean: the past 10 years. Rev. Panam. Salud Publica 32, 15-21 (2012).

87. Pereira, M., Lunet, N., Azevedo, A. \& Barros, H. Differences in prevalence, awareness, treatment and control of hypertension between developing and developed countries. J. Hypertens. 27, 963-975 (2009).

88. Ikeda, N. et al. Control of hypertension with medication: a comparative analysis of national surveys in 20 countries. Bull. World Health Organ 92, 10-19C (2014).

89. Yang, F et al. Prevalence, awareness, treatment, and control of hypertension in the older population results from the multiple national studies on ageing J. Am. Soc. Hypertens. 10, 140-148 (2016).

90. Roulet, C. et al. Secular trends in blood pressure in children: a systematic review. J. Clin. Hypertens. 19, 488-497 (2017)

91. Irazola, V. E. et al. Hypertension prevalence, awareness, treatment, and control in selected LMIC communities: results from the NHLBI/UHG network of Centers of Excellence for Chronic Diseases. Glob. Heart 11 47-59 (2016).

92. Geldsetzer, P. et al. The state of hypertension care in 44 low-income and middle-income countries: a cross-sectional study of nationally representative individual-level data from 1.1 million adults. Lancet 394, 652-662 (2019).

93. McCarron, P., Smith, G. D. \& Okasha, M. Secular changes in blood pressure in childhood, adolescence and young adulthood: systematic review of trends from 1948 to 1998. J. Hum. Hypertens. 16, 677-689 (2002).

94. Wolf-Maier, K. et al. Hypertension prevalence and blood pressure levels in 6 European countries, Canada, and the United States. JAMA 289 2363-2369 (2003)

95. NCD Risk Factor Collaboration (NCD-RisC) Long-term and recent trends in hypertension awareness, treatment, and control in 12 high-income countries: an analysis of 123 nationally representative surveys. Lancet 394, 639-651 (2019).

96. Kearney, P. M., Whelton, M., Reynolds, K., Whelton, P. K. \& He, J. Worldwide prevalence of hypertension: a systematic review. J. Hypertens. 22 11-19 (2004)

97. Kearney, P. M. et al. Global burden of hypertension: analysis of worldwide data. Lancet 365, 217-223 (2005).

98. Mills, K. T. et al. Global disparities of hypertension prevalence and control: a systematic analysis of population-based studies from 90 countries. Circulation 134, 441-450 (2016).

99. Lawes, C. M. et al. Blood pressure and the global burden of disease 2000. Part 1: estimates of blood pressure levels. J. Hypertens. 24, 413-422 (2006)

100. Danaei, G. et al. National, regional, and global trends in systolic blood pressure since 1980: systematic analysis of health examination surveys and epidemiological studies with 786 country-years and 5.4 million participants. Lancet $377,568-577$ (2011).
101. Forouzanfar, M. H. et al. Global burden of hypertension and systolic blood pressure of at least 110 to $115 \mathrm{~mm} \mathrm{Hg}, 1990-2015$. JAMA 317, 165-182 (2017)

102. NCD Risk Factor Collaboration (NCD-RisC). Worldwide trends in blood pressure from 1975 to 2015: a pooled analysis of 1479 population-based measurement studies with 19.1 million participants. Lancet 389 , 37-55 (2017)

103. Sacks, F. M. \& Campos, H. Dietary therapy in hypertension. N. Engl. J. Med. 362, 2102-2112 (2010).

104. Danaei, G. et al. The global cardiovascular risk transition: associations of four metabolic risk factors with national income, urbanization, and Western diet in 1980 and 2008. Circulation 127, 1493-1502 (2013).

105. Ezzati, M. et al. Rethinking the "diseases of affluence" paradigm: global patterns of nutritional risks in relation to economic development. PLoS Med. 2 , e133 (2005).

106. Bentham, J. et al. Multidimensional characterization of global food supply from 1961 to 2013. Nat. Food 1, 70-75 (2020)

107. Gregg, E. W. et al. Secular trends in cardiovascular disease risk factors according to body mass index in US adults. JAMA 293, 1868-1874 (2005).

108. Micha, R. et al. Global, regional and national consumption of major food groups in 1990 and 2010 a systematic analysis including 266 country-specific nutrition surveys worldwide. BMJ Open 5, e008705 (2015).

109. Powles, J. et al. Global, regional and national sodium intakes in 1990 and 2010: a systematic analysis of $24 \mathrm{~h}$ urinary sodium excretion and dietary surveys worldwide. BMJ Open 3, e003733 (2013).

110. NCD Risk Factor Collaboration (NCD-RisC). Worldwide trends in body-mass index, underweight, overweight, and obesity from 1975 to 2016: a pooled analysis of 2416 population-based measurement studies in 128.9 million children, adolescents, and adults. Lancet 390, 2627-2642 (2017).

111. Stevens, G. A. et al. Trends in mild, moderate and severe stunting and underweight, and progress towards MDG 1 in 141 developing countries: a systematic analysis of population representative data. Lancet 380, 824-834 (2012).

112. NCD Risk Factor Collaboration (NCD-RisC). A century of trends in adult human height. eLife 5, e13410 (2016).

113. Victora, C. G. et al. Maternal and child undernutrition: consequences for adult health and human capital. Lancet 371, 340-357 (2008).

114. He, F. J., Li, J. \& Macgregor, G. A. Effect of longer term modest salt reduction on blood pressure: Cochrane systematic review and meta-analysis of randomised trials. BMJ 346, f1325 (2013).

115. Aburto, N. J. et al. Effect of increased potassium intake on cardiovascular risk factors and disease: systematic review and meta-analyses. BMJ 346, f1378 (2013).

116. Roerecke, M. et al. The effect of a reduction in alcohol consumption on blood pressure: a systematic review and meta-analysis. Lancet Public Health 2 e 108-e120 (2017)

117. Virdis, A., Giannarelli, C., Neves, M. F., Taddei, S. \& Ghiadoni, L. Cigarette smoking and hypertension. Curr. Pharm. Des. 16, 2518-2525 (2010)

118. Cornelissen, V. A. \& Smart, N. A. Exercise training for blood pressure: a systematic review and meta-analysis. J. Am. Heart Assoc. 2, e004473 (2013)

119. Cai, Y. et al. Associations of short-term and long-term exposure to ambient air pollutants with hypertension: a systematic review and meta-analysis. Hypertension 68, 62-70 (2016)

120. Munzel, T., Gori, T., Babisch, W. \& Basner, M. Cardiovascular effects of environmental noise exposure. Eur. Heart J. 35, 829-836 (2014).

121. Gasperin, D., Netuveli, G., Dias-da-Costa, J. S. \& Pattussi, M. P. Effect of psychological stress on blood pressure increase: a meta-analysis of cohort studies. Cad. Saude Publica 25, 715-726 (2009).

122. NCD Risk Factor Collaboration (NCD-RisC). Contributions of mean and shape of blood pressure distribution to worldwide trends and variations in raised blood pressure: a pooled analysis of 1018 population-based measurement studies with 88.6 million participants. Int. J. Epidemiol. 47, 872-883i (2018).

123. He, F. J., Pombo-Rodrigues, S. \& Macgregor, G. A Salt reduction in England from 2003 to 2011 : its relationship to blood pressure, stroke and ischaemic heart disease mortality. BMJ Open 4, e004549 (2014).

124. Ikeda, N., Gakidou, E., Hasegawa, T. \& Murray, C. J. Understanding the decline of mean systolic blood pressure in Japan: an analysis of pooled data from the National Nutrition Survey, 1986-2002. Bull. World Health Organ. 86, 978-988 (2008).

125. Laatikainen, T. et al. Sodium in the Finnish diet: 20 -year trends in urinary sodium excretion among the adult population. Eur. J. Clin. Nutr. 60, 965-970 (2006).

126. Du, S. et al. Understanding the patterns and trends of sodium intake, potassium intake, and sodium to potassium ratio and their effect on hypertension in China. Am. J. Clin. Nutr. 99, 334-343 (2014)

127. Bernstein, A. M. \& Willett, W. C. Trends in 24-h urinary sodium excretion in the United States, 1957-2003: a systematic review. Am. J. Clin. Nutr. 92, 1172-1180 (2010)

128. Lee, H. S., Duffey, K. J. \& Popkin, B. M. Sodium and potassium intake patterns and trends in South Korea. J. Hum. Hypertens. 27, 298-303 (2013).

129. Johnson, C. et al. Mean population salt consumption in India: a systematic review. J. Hypertens. 35, 3-9 (2017).

130. Sarno, F., Claro, R. M., Levy, R. B., Bandoni, D. H. \& Monteiro, C. A. Estimated sodium intake for the Brazilian population, 2008-2009 [Portuguese]. Rev. Saude Publica 47, 571-578 (2013)

131. Bilano, V. et al. Global trends and projections for tobacco use, 1990-2025: an analysis of smoking indicators from the WHO Comprehensive Information Systems for Tobacco Control. Lancet 385, 966-976 (2015).

132. World Health Organization. Global status report on slcohol and health (WHO, 2014).

133. Lewington, S. et al. Seasonal variation in blood pressure and its relationship with outdoor temperature in 10 diverse regions of China: the China Kadoorie Biobank. J. Hypertens. 30, 1383-1391 (2012).

134. Saeki, K. et al. Influence of room heating on ambulatory blood pressure in winter: a randomised controlled study. J. Epidemiol. Community Health 67 484-490 (2013).

135. Wang, Q. et al. Environmental ambient temperature and blood pressure in adults: a systematic review and meta-analysis. Sci. Total Environ. 575, 276-286 (2017).

136. Dong, B., Wang, Z., Song, Y., Wang, H. J. \& Ma, J. Understanding trends in blood pressure and their associations with body mass index in Chinese children, from 1985 to 2010: a cross-sectional observational study. BMJ Open 5, e009050 (2015).

137. Khang, Y. H. \& Lynch, J. W. Exploring determinants of secular decreases in childhood blood pressure and hypertension. Circulation 124, 397-405 (2011)

138. Chiolero, A. et al. Discordant secular trends in elevated blood pressure and obesity in children and adolescents in a rapidly developing country. Circulation 119, 558-565 (2009).

139. Xi, B. et al. Trends in elevated blood pressure among US children and adolescents: 1999-2012. Am. J. Hypertens. 29, 217-225 (2016).

140. Reckelhoff, J. F. Gender differences in the regulation of blood pressure. Hypertension 37, 1199-1208 (2001)

141. Marmot, M. G. et al. Health inequalities among British civil servants: the Whitehall II study. Lancet 337 1387-1393 (1991).

142. Colhoun, H. M., Hemingway, H. \& Poulter, N. R Socio-economic status and blood pressure: an overview analysis. J. Hum. Hypertens. 12, 91-110 (1998).

143. Ezzati, M., Oza, S., Danaei, G. \& Murray, C. J. Trends and cardiovascular mortality effects of statelevel blood pressure and uncontrolled hypertension in the United States. Circulation 117, 905-914 (2008).

144. Danaei, G. et al. The promise of prevention: the effects of four preventable risk factors on national life expectancy and life expectancy disparities by race and county in the United States. PLoS Med. 7, e1000248 (2010).

145. Di Cesare, M. et al. Inequalities in non-communicable diseases and effective responses. Lancet 381 , 585-597 (2013)

146. Bennett, S. Cardiovascular risk factors in Australia: trends in socioeconomic inequalities. J. Epidemiol. Community Health 49, 363-372 (1995).

147. Peltonen, M., Huhtasaari, F., Stegmayr, B., Lundberg, V. \& Asplund, K. Secular trends in social patterning of cardiovascular risk factor levels in Sweden. The Northern Sweden MONICA Study 
1986-1994. Multinational Monitoring of Trends and Determinants in Cardiovascular Disease. J. Intern. Med. 244, 1-9 (1998).

148. Bartley, M., Fitzpatrick, R., Firth, D. \& Marmot, M Social distribution of cardiovascular disease risk factors: change among men in England 1984-1993. J. Epidemiol. Community Health 54, 806-814 (2000).

149. Ferrario, M. et al. Time trends of major coronary risk factors in a northern Italian population (1986-1994). How remarkable are socioeconomic differences in an industrialized low CHD incidence country? Int. J. Epidemiol. 30, 285-297 (2001).

150. Galobardes, B., Costanza, M. C., Bernstein, M. S. Delhumeau, C. \& Morabia, A. Trends in risk factors for lifestyle-related diseases by socioeconomic position in Geneva, Switzerland, 1993-2000: health inequalities persist. Am. J. Public Health 93, 1302-1309 (2003)

151. Kanjilal, S. et al. Socioeconomic status and trends in disparities in 4 major risk factors for cardiovascular disease among US adults, 1971-2002. Arch. Intern Med. 166, 2348-2355 (2006).

152. Scholes, S. et al. Persistent socioeconomic inequalities in cardiovascular risk factors in England over 1994-2008: a time-trend analysis of repeated cross-sectional data. BMC Public Health 12, 129 (2012).

153. Bleich, S. N., Jarlenski, M. P., Bell, C. N. \& LaVeist, T. A. Health inequalities: trends, progress, and policy. Annu. Rev. Public Health 33, 7-40 (2012).

154. SarrafZadegan, N. \& AminiNik, S. Blood pressure pattern in urban and rural areas in Isfahan, Iran. J. Hum. Hypertens. 11, 425-428 (1997).

155. Agyemang, C. Rural and urban differences in blood pressure and hypertension in Ghana, West Africa. Public Health 120, 525-533 (2006).

156. Addo, J., Smeeth, L. \& Leon, D. A. Hypertension in sub-saharan Africa: a systematic review. Hypertension 50, 1012-1018 (2007).

157. Conen, D., Glynn, R. J., Ridker, P. M., Buring, J. E. $\&$ Albert, M. A. Socioeconomic status, blood pressure progression, and incident hypertension in a prospective cohort of female health professionals. Eur. Heart J. 30, 1378-1384 (2009).

158. Brummett, B. H. et al. Systolic blood pressure, socioeconomic status, and biobehavioral risk factors in a nationally representative US young adult sample. Hypertension 58, 161-166 (2011).

159. Cois, A. \& Ehrlich, R. Analysing the socioeconomic determinants of hypertension in South Africa: a structural equation modelling approach. BMC Public Health 14, 414 (2014).

160. Li, J. et al. Urban-rural disparities in hypertension prevalence, detection, and medication use among Chinese adults from 1993 to 2011. Int. J. Equity Health 16, 50 (2017).

161. Osler, M. et al. Socioeconomic status and trends in risk factors for cardiovascular diseases in the Danish MONICA population, 1982-1992. J. Epidemiol. Community Health 54, 108-113 (2000).

162. Damasceno, A. et al. Hypertension prevalence, awareness, treatment, and control in Mozambique: urban/rural gap during epidemiological transition. Hypertension 54, 77-83 (2009).

163. Stringhini, S., Viswanathan, B., Gedeon, J., Paccaud, F. $£$ Bovet, P. The social transition of risk factors for cardiovascular disease in the African region: evidence from three cross-sectional surveys in the Seychelles. Int. J. Cardiol. 168, 1201-1206 (2013).

164. Basit, A., Tanveer, S., Fawwad, A., Naeem, N. \& NDSP Members. Prevalence and contributing risk factors for hypertension in urban and rural areas of Pakistan; a study from second National Diabetes Survey of Pakistan (NDSP) 2016-2017. Clin. Exp. Hypertens. 42, 218-224 (2020)

165. Padmavati, S. \& Gupta, S. Blood pressure studies in rural and urban groups in Delhi. Circulation 19 395-405 (1959).

166. Shaper, A. G. Cardiovascular disease in the tropics. 3. Blood pressure and hypertension. Br. Med. J. 3 , 805-807 (1972)

167. Sarki, A. M., Nduka, C. U., Stranges, S., Kandala, N. B. \& Uthman, O. A. Prevalence of hypertension in low- and middle-income countries: a systematic review and meta-analysis. Medicine 94, e1959 (2015).

168. Leng, B., Jin, Y., Li, G., Chen, L. \& Jin, N. Socioeconomic status and hypertension: a meta-analysis. J. Hypertens. 33, 221-229 (2015).

169. Murray, C. J. \& Lopez, A. D. Global mortality, disability, and the contribution of risk factors: Global Burden of Disease Study. Lancet 349, 1436-1442 (1997).
170. Ezzati, M., Lopez, A. D., Rodgers, A., Vander Hoorn, S. \& Murray, C. J. Selected major risk factors and global and regional burden of disease. Lancet 360 , 1347-1360 (2002).

171. Lim, S. S. et al. A comparative risk assessment of burden of disease and injury attributable to 67 risk factors and risk factor clusters in 21 regions, 1990-2010: a systematic analysis for the Global Burden of Disease Study 2010. Lancet 380 , 2224-2260 (2012).

172. GBD Risk Factor Collaborators. Global, regional, and national comparative risk assessment of 84 behavioural, environmental and occupational, and metabolic risks or clusters of risks for 195 countries and territories, 1990-2017: a systematic analysis for the Global Burden of Disease Study 2017. Lancet 392, 1923-1994 (2018).

173. Labarthe, D. \& Ayala, C. Nondrug interventions in hypertension prevention and control. Cardiol. Clin. 20 249-263 (2002)

174. Asaria, P., Chisholm, D., Mathers, C., Ezzati, M. \& Beaglehole, R. Chronic disease prevention: health effects and financial costs of strategies to reduce salt intake and control tobacco use. Lancet 370 , 2044-2053 (2007).

175. Prabhakaran, D. et al. Cardiovascular, respiratory, and related disorders: key messages from Disease Control Priorities, 3rd edition. Lancet 391 , 1224-1236 (2018)

176. World Health Organization. Global action plan for the prevention and control of noncommunicable diseases 2013-2020 (WHO, 2013).

177. Rabi, D. M. et al. Hypertension Canada's 2020 comprehensive guidelines for the prevention diagnosis, risk assessment, and treatment of hypertension in adults and children. Can. J. Cardiol. 36, 596-624 (2020).

178. Williams, B. et al. 2018 ESC/ESH guidelines for the management of arterial hypertension. Eur. Heart $\mathrm{J}$. 39, 3021-3104 (2018)

179. Carey, R. M., Muntner, P., Bosworth, H. B. \& Whelton, P. K. Prevention and control of hypertension JACC Health Promotion Series. J. Am. Coll. Cardiol. 72, 1278-1293 (2018)

180. Wilson, E. et al. Platform for international action on cardiovascular disease. Prev. Control. 1, 185-217 (2005).

181. Jorgensen, T. et al. Population-level changes to promote cardiovascular health. Eur. J. Prev. Cardiol. 20, 409-421 (2013)

182. He, F. J. \& MacGregor, G. A. Role of salt intake in prevention of cardiovascular disease: controversies and challenges. Nat. Rev. Cardiol. 15, 371-377 (2018).

183. Thomopoulos, C., Parati, G. $\&$ Zanchetti, A. Effects of blood pressure lowering on outcome incidence in hypertension. 1. Overview, meta-analyses, and metaregression analyses of randomized trials. J. Hypertens. 32, 2285-2295 (2014)

184. Unger, T. et al. 2020 International Society of Hypertension global hypertension practice guidelines Hypertension 75, 1334-1357 (2020).

185. Joint Committee for Guideline Revision. 2018 Chinese guidelines for prevention and treatment of hypertension-A report of the Revision Committee of Chinese Guidelines for Prevention and Treatment of Hypertension. J. Geriatr. Cardiol. 16, 182-241 (2019).

186. Shah, S. N. et al. Indian guidelines on hypertension-IV (2019). J. Hum. Hypertens. 34, 745-758 (2020)

187. Division of Non-Communicable Diseases. Kenya national guidelines for cardiovascular diseases management (Ministry of Health, 2018).

188. National Institute for Health and Clinical Excellence. Hypertension in adults: diagnosis and management. NICE guideline [NG136] (NICE, 2019).

189. Whelton, P. K. et al. 2017 ACC/AHA/AAPA/ABC/ ACPM/AGS/APhA/ASH/ASPC/NMA/PCNA guideline for the prevention, detection, evaluation, and management of high blood pressure in adults: Executive Summary: a report of the American College of Cardiology/American Heart Association Task Force. Hypertension 71, 1269-1324 (2018).

190. Wald, D. S., Law, M., Morris, J. K., Bestwick, J. P. \& Wald, N. J. Combination therapy versus monotherapy in reducing blood pressure: meta-analysis on 11,000 participants from 42 trials. Am. J. Med. 122 , 290-300 (2009)

191. Gupta, A. K., Arshad, S. \& Poulter, N. R. Compliance, safety, and effectiveness of fixed-dose combinations of antihypertensive agents: a meta-analysis. Hypertension 55, 399-407 (2010)
192. Kaptoge, S. et al. World Health Organization cardiovascular disease risk charts: revised models to estimate risk in 21 global regions. Lancet Glob. Health 7, e1332-e1345 (2019)

193. Vedanthan, R. et al. Innovative approaches to hypertension control in low- and middle-income countries. Cardiol. Clin. 35, 99-115 (2017).

194. Feldman, R. D. et al. A simplified approach to the treatment of uncomplicated hypertension: a cluste randomized, controlled trial. Hypertension $\mathbf{5 3}$ 646-653 (2009)

195. Angell, S. Y., De Cock, K. M. \& Frieden, T. R. A public health approach to global management of hypertension. Lancet 385, 825-827 (2015).

196. Patel, P. et al. Improved blood pressure control to reduce cardiovascular disease morbidity and mortality: the Standardized Hypertension Treatment and Prevention Project. J. Clin. Hypertens. 18, 1284-1294 (2016).

197. Attaei, M. W. et al. Availability and affordability of blood pressure-lowering medicines and the effect on blood pressure control in high-income, middle-income and low-income countries: an analysis of the PURE study data. Lancet Public Health 2, e411-e419 (2017).

198. Jaffe, M. G., Lee, G. A., Young, J. D., Sidney, S. \& Go, A. S. Improved blood pressure control associated with a large-scale hypertension program. JAMA 310, 699-705 (2013).

199. Padwal, R. S., Bienek, A., McAlister, F. A. Campbell, N. R. \& Outcomes Research Task Force of the Canadian Hypertension Education Program. Epidemiology of hypertension in Canada: an update. Can. J. Cardiol. 32, 687-694 (2016).

200. Campbell, N. R. \& Sheldon, T. The Canadian effort to prevent and control hypertension: can other countries adopt Canadian strategies? Curr. Opin. Cardiol. 25, 366-372 (2010)

201. Anand, T. N., Joseph, L. M., Geetha, A. V., Prabhakaran, D. \& Jeemon, P. Task sharing with non-physician health-care workers for management of blood pressure in low-income and middle-income countries: a systematic review and meta-analysis. Lancet Glob. Health 7, e761-e771 (2019).

202. McAlister, F. A. The Canadian Hypertension Education Program-a unique Canadian initiative. Can. J. Cardiol. 22, 559-564 (2006)

203. He, J. et al. Effect of a community health worker-led multicomponent intervention on blood pressure control in low-income patients in Argentina: a randomized clinical trial. JAMA 318, 1016-1025 (2017).

204. Victor, R. G. et al. A cluster-randomized trial of bloodpressure reduction in black barbershops. N. Engl. J. Med. 378, 1291-1301 (2018).

205. Lu, X. et al. Interactive mobile health intervention and blood pressure management in adults. Hypertension 74, 697-704 (2019).

206. Schwalm, J.-D. et al. A community-based comprehensive intervention to reduce cardiovascular risk in hypertension (HOPE 4): a cluster-randomised controlled trial. Lancet 394, 1231-1242 (2019).

207. Shariful Islam, S. M. et al. Mobile phone text-messaging interventions aimed to prevent cardiovascular diseases (Text2PreventCVD): systematic review and individual patient data meta-analysis. Open. Heart 6, e001017 (2019).

208. Jafar, T. H. et al. A community-based intervention for managing hypertension in rural South Asia. N. Engl. J. Med. 382, 717-726 (2020).

209. Sherrill, B., Halpern, M., Khan, S., Zhang, J. \& Panjabi, S. Single-pill vs free-equivalent combination therapies for hypertension: a meta-analysis of health care costs and adherence. J. Clin. Hypertens. 13 898-909 (2011).

210. Chow, C. K et al. Quarter-dose quadruple combination therapy for initial treatment of hypertension: placebo-controlled, crossover, randomised trial and systematic review. Lancet 389, 1035-1042 (2017)

211. Noah, B. et al. Impact of remote patient monitoring on clinical outcomes: an updated meta-analysis of randomized controlled trials. NPJ Digit. Med. 1, 20172 (2018)

212. Timpel, P., Oswald, S., Schwarz, P. E. H. \& Harst, L. Mapping the evidence on the effectiveness of telemedicine interventions in diabetes, dyslipidemia, and hypertension: an umbrella review of systematic reviews and meta-analyses. J. Med. Internet Res. 22, e16791 (2020). 
213. Zullig L L., Melnyk, S. D Goldstein, K Shaw, R. J. \& Bosworth, H. B. The role of home blood pressure telemonitoring in managing hypertensive populations. Curr. Hypertens. Rep. 15, 346-355 (2013).

214. Alessa, T., Hawley, M. S., Hock, E. S. \& de Witte, L. Smartphone apps to support self-management of hypertension: review and content analysis. JMIR Mhealth Uhealth 7, e13645 (2019).

215. Kitt, J., Fox, R., Tucker, K. L. \& McManus, R. J. New approaches in hypertension management: a review of current and developing technologies and their potential impact on hypertension care. Curr. Hypertens. Rep. 21, 44 (2019).

216. Li, R., Liang, N., Bu, F. \& Hesketh, T. The effectiveness of self-management of hypertension in adults using mobile health: systematic review and meta-analysis. JMIR Mhealth Uhealth 8, e 17776 (2020).

217. World Health Organization. Global Hearts Initiative, working together to promote cardiovascular health (WHO, 2018).

218. Adler, A. J. et al. Reducing cardiovascular mortality through prevention and management of raised blood pressure: a World Heart Federation roadmap. Glob. Heart 10, 111-122 (2015).

219. Dzudie, A. et al. Roadmap to achieve $25 \%$ hypertension control in Africa by 2025. Cardiovasc. J. Afr. 28, 262-272 (2017)

220. Frieden, T. R. \& Bloomberg, M. R. Saving an additional 100 million lives. Lancet 391, 709-712 (2018)

221. The World Bank. Tracking universal health coverage: 2017 global monitoring report (The World Bank, 2017).

222. Guan, W. J. et al. Comorbidity and its impact on 1590 patients with COVID-19 in China: a nationwide analysis. Eur. Respir. J. 55, 2000547 (2020).

223. Zhou, F. et al. Clinical course and risk factors for mortality of adult inpatients with COVID-19 in Wuhan China: a retrospective cohort study. Lancet 395 , 1054-1062 (2020)

224. Chudasama, Y. V. et al. Multimorbidity and SARS CoV-2 infection in UK Biobank. Diabetes Metab. Syndr. 14, 775-776 (2020)

225. Richardson, S. et al. Presenting characteristics, comorbidities, and outcomes among 5700 patients hospitalized with COVID-19 in the New York City area. JAMA 323, 2052-2059 (2020).

226. Rodriguez-Morales, A. J. et al. Clinical, laboratory and imaging features of COVID-19: a systematic review and meta-analysis. Travel Med. Infect. Dis. 34, 101623 (2020)

227. Yang, J. et al. Prevalence of comorbidities and its effects in patients infected with SARS-CoV-2: a systematic review and meta-analysis. Int. J. Infect. Dis. 94, 91-95 (2020).

228. Garg, S. et al. Hospitalization rates and characteristics of patients hospitalized with laboratory-confirmed coronavirus disease 2019 - COVID-NET, 14 states, March 1-30, 2020. MMWR 69, 458-464 (2020)

229. Singh, A. K. et al. Prevalence of co-morbidities and their association with mortality in patients with COVID-19: a systematic review and metaanalysis. Diabetes Obes. Metab. 22, 1915-1924 (2020).

230. Hamer, M., Gale, C. R., Kivimaki, M. \& Batty, G. D. Overweight obesity, and risk of hospitalization for COVID-19: a community-based cohort study of adults in the United Kingdom. Proc. Natl Acad. Sci. USA 117 21011-21013 (2020)

231. Gao, C. et al. Association of hypertension and antihypertensive treatment with COVID-19 mortality: a retrospective observational study. Eur. Heart J. 41, 2058-2066 (2020)
232. Atkins, J. L. et al. Preexisting comorbidities predicting COVID-19 and mortality in the UK Biobank Community Cohort. J. Gerontol. A 75, 2224-2230 (2020).

233. Williamson, E. J. et al. Factors associated with COVID-19-related death using OpenSAFELY. Nature 584, 430-436 (2020).

234. laccarino, G. et al. Age and multimorbidity predict death among COVID-19 patients: results of the SARS-RAS study of the Italian Society of Hypertension. Hypertension 76, 366-372 (2020).

235. Schiffrin, E. L., Flack, J. M., Ito, S., Muntner, P. \& Webb, R. C. Hypertension and COVID-19. Am. J. Hypertens. 33, 373-374 (2020).

236. Cariou, B. et al. Phenotypic characteristics and prognosis of inpatients with COVID-19 and diabetes: the CORONADO study. Diabetologia 63, 1500-1515 (2020).

237. Zheng, Z. et al. Risk factors of critical \& mortal COVID-19 cases: a systematic literature review and meta-analysis. J. Infect. 81, e 16-e25 (2020).

238. Wrapp, D. et al. Cryo-EM structure of the 2019-nCoV spike in the prefusion conformation. Science 367 1260-1263 (2020).

239. Fang, L., Karakiulakis, G. \& Roth, M. Are patients with hypertension and diabetes mellitus at increased risk for COVID-19 infection? Lancet Respir. Med. 8, e21 (2020).

240. de Abajo, F. J. et al. Use of renin-angiotensinaldosterone system inhibitors and risk of COVID-19 requiring admission to hospital: a case-population study. Lancet 395, 1705-1714 (2020).

241. Mehta, N. et al. Association of use of angiotensin converting enzyme inhibitors and angiotensin II receptor blockers with testing positive for coronavirus disease 2019 (COVID-19). JAMA Cardiol. 5 , 1020-1026 (2020)

242. Hypertension Canada. Hypertension Canada's statement on: hypertension, ACE-inhibitors and angiotensin receptor blockers and COVID-19. Hypertension Canada https://hypertension.ca/media/ (2020).

243. Kario, K. et al. COVID-19 and hypertension-evidence and practical management: Guidance from the HOPE Asia Network. J. Clin. Hypertens. 22, 1109-1119 (2020).

244. Shibata, S. et al. Hypertension and related diseases in the era of COVID-19: a report from the Japanese Society of Hypertension Task Force on COVID-19. Hypertens. Res. 43, 1028-1046 (2020)

245. American College of Cardiology. HFSA/ACC/AHA Statement addresses concerns re: using RAAS antagonists in COVID-19 (ACC, 2020)

246. European Society of Cardiology. Position statement of the ESC Council on hypertension on ACE-inhibitors and angiotensin receptor blockers (ESC, 2020).

247. Kreutz, R. et al. Hypertension, the renin-angiotensin system, and the risk of lower respiratory tract infections and lung injury: implications for COVID-19. Cardiovasc. Res. 116, 1688-1699 (2020).

248. National Institute for Health and Clinical Excellence. Angiotensin converting enzyme inhibitors (ACEIs) or angiotensin receptor blockers (ARBs) in people with or at risk of COVID-19 (NICE, 2020).

249. Baral, R., White, M. \& Vassiliou, V. S. Effect of reninangiotensin-aldosterone system inhibitors in patients with COVID-19: a systematic review and meta-analysis of 28,872 patients. Curr. Atheroscler. Rep. 22, 61 (2020).

250. Hippisley-Cox, J. et al. Risk of severe COVID-19 disease with ACE inhibitors and angiotensin receptor blockers: cohort study including 8.3 million people. Heart 106, 1503-1511 (2020).
251. Mancia, G., Rea, F., Ludergnani, M., Apolone G. \& Corrao, G. Renin-angiotensin-aldosterone system blockers and the risk of Covid-19. N. Engl. J. Med. 382, 2431-2440 (2020)

252. Wang, J. J. et al. Good or bad: application of RAAS inhibitors in COVID-19 patients with cardiovascular comorbidities. Pharmacol. Ther. 215, 107628 (2020)

253. Kluge, H. H. P. et al. Prevention and control of noncommunicable diseases in the COVID-19 response. Lancet 395, 1678-1680 (2020).

254. Nadar, S. K., Tayebjee, M. H. Stowasser, M. $\&$ Byrd, J. B. Managing hypertension during the COVID-19 pandemic. J. Hum. Hypertens. 34 415-417 (2020).

255. Chudasama, Y. V. et al. Impact of COVID-19 on routine care for chronic diseases: a global survey of views from healthcare professionals. Diabetes Metab. Syndr. 14, 965-967 (2020).

256. World Health Organization. The impact of the COVID-19 pandemic on noncommunicable disease resources and services: results of a rapid assessment (WHO, 2020).

257. Wright, A., Salazar, A., Mirica, M., Volk, L. A. \& Schiff, G. D. The invisible epidemic: neglected chronic disease management during COVID-19. J. Gen. Intern. Med. 35, 2816-2817 (2020).

258. British Medical Association. The hidden impact of COVID-19 on patient care in the NHS in England (BMA, 2020).

259. Douglas, M., Katikireddi, S. V., Taulbut, M., McKee, M. $\&$ McCartney, G. Mitigating the wider health effects of covid-19 pandemic response. BMJ 369, m 1557 (2020).

260. Tison, G. H. et al. Worldwide effect of COVID-19 on physical activity: a descriptive study. Ann. Intern. Med. 173, 767-770 (2020)

261. Kontis, V. et al. Magnitude, demographics and dynamics of the effect of the first wave of the COVID-19 pandemic on all-cause mortality in 21 industrialized countries. Nat. Med. 26, 1919-1928 (2020).

Acknowledgements

B.Z. is supported by an Institutional Strategic Support Fund Springboard Fellowship from the Wellcome Trust.

\section{Author contributions}

B.Z. researched data for the article. All the authors contributed to discussion of the content, wrote the article and reviewed and/or edited the manuscript before submission.

\section{Competing interests}

M.E. reports a charitable grant from the AstraZeneca Young Health Programme and personal fees from Prudential, unrelated to this Review. The other authors declare no competing interests.

Peer review information

Nature Reviews Cardiology thanks D. Arnett and C. Tsioufis for their contribution to the peer review of this work.

\section{Publisher's note}

Springer Nature remains neutral with regard to jurisdictional claims in published maps and institutional affiliations.

Supplementary information

The online version contains supplementary material available at https://doi.org/10.1038/s41569-021-00559-8.

RELATED LINKS

NCD-RisC: www.ncdrisc.org

C) Springer Nature Limited 2021 